\title{
Review Article \\ High Performance Damage-Resistant Seismic Resistant Structural Systems for Sustainable and Resilient City: A Review
}

\author{
Junhua Wang $\mathbb{D}^{1,2}$ and Hua Zhao $\mathbb{D}^{2}$ \\ ${ }^{1}$ College of Civil Engineering, Nanjing Tech University, Nanjing, Jiangsu, China \\ ${ }^{2}$ State Key Laboratory of Geohazard Prevention and Geoenvironment Protection, Chengdu University of Technology, \\ Chengdu, Sichuan, China
}

Correspondence should be addressed to Hua Zhao; zardhua@gmail.com

Received 14 July 2017; Revised 11 December 2017; Accepted 10 January 2018; Published 30 April 2018

Academic Editor: Mohamed ElGawady

Copyright (C) 2018 Junhua Wang and Hua Zhao. This is an open access article distributed under the Creative Commons Attribution License, which permits unrestricted use, distribution, and reproduction in any medium, provided the original work is properly cited.

\begin{abstract}
This paper presents a review of high performance damage-resistant seismic resistant structural (DRSRS) systems for the sustainable and resilient city. Firstly, the motivation and the basic principle as well as methodology of the developing DRSRS system are briefly illustrated. Then, the structural detailing and the seismic behaviors of three types of existing DRSRS systems, namely, the replaceable structural element (RSE), rocking seismic resisting structural (RSRS) system, and self-centering seismic resisting structural (SCSRS) system, are summarized in detail. The theoretical and extensive experimental study results indicated that the three existing types of DRSRS system can minimize the postdamage after loading. Types of energy dissipation devices and dampers, as well as fuse sections, can largely enhance the energy dissipation capacity of the proposed structural system. Many numerical and finite element models have been proposed to analyze the dynamic and static cyclic responses of them. The residual deformation after the dynamic response is smaller compared to that following the cyclic response. Then, the current research challenges of DRSRS system are illustrated, and the new research highlights that emerged in recent years are stated. Finally, the conclusions of this paper are summarized; furthermore, the recommendations for the future studies are pointed out at the end of the paper.
\end{abstract}

\section{Introduction}

The majority of the world's population, over 3.96 billion people, lives in cities [1]. As the centers of population, politics, and economics activity as well as culture, the natural hazards bring more severe destructions and disasters to cities compared to before. Therefore, the sustainable and resilient city has been paid more and more enthusiasm in recent years. A "resilient city" is demanded to quickly rehabilitate or maintain its essential functions from any shock or stress [2]. The shocks or stresses include heat waves, storms, earthquake, flood, and an accelerated rate of sea level rise.

The Wenchuan earthquake in 2008 caused 86000 deaths and approximately 138.33 billion USD economical loss [3]. The Great Kobe earthquake led 6434 deaths and caused about 170 billion USD loss in economics [4]. 15870 persons died in the Great East Japan Earthquake which caused about 100 billion loss USD in economics [5]. The 7.8 magnitude earthquake in Nepal in April 2015 occurred with close to 9,000 victims and 6 billion USD estimated losses including damage reported in India, China, and Bangladesh [6]. On 16 April 2016, a series of earthquakes hit Kumamoto, Japan, leading to 64 deaths and infrastructure damage of approximately 5.6 billion USD. On the same day, an earthquake attacked Ecuador and murdered 668 people [7]. In August 2016, Italy's Umbria region suffered from a 6.2 earthquake that caused 293 deaths and left 4000 people homeless; the damage is estimated at 3.96 billion USD [8]. Other invisible losses in culture, human emotion, and quality of life are inestimable.

The earthquake caused a mass of economical loss and destructions of infrastructures; this leads to big difficulty for the sustainable and resilient city. Thus the American and Japanese earthquake engineering researchers pointed out that the resilient city needs to be the next objective of 
earthquake engineering at the seventh joint planning meeting of NEES/E-Defense Collaborative Research on Earthquake Engineering [9]. Actually, to minimize the residual deformation of engineering structure after an earthquake, engineers and researchers have developed some innovative structure systems including replaceable structural element (RSE) and rocking seismic resisting structural (RSRC) system as well as self-centering seismic resisting structural (SCSRS) system in recent decades; all the above-mentioned structural systems are called high performance damage-resistant seismic structural (DRSS) system in this paper.

The RSE is developed through actively artificially forming relative weakening structural element which will be easily failed before other protective structural elements and can be easily replaced after an earthquake; as a result, the whole structure can be quickly rehabilitated and desterilized. So far, the most popular studied DRSRS systems are RCRC system and SCSRS system that is created in accordance with the elastic gap opening mechanisms to soften the seismic response of the structure; posttension tendon or strand is used to return the whole structure to a plumb position. In order to dissipate the seismic energy, the energy dissipating devices or types of dampers are usually included in the DRSRS system. In addition, using the inherent strong elastic recovery force of high strength tension longitudinal bar to pull the structure back after loading is another new way to develop the DRSRS system in recent years.

The objectives of this paper are to review the current research status of high performance DRSRS systems and to outline current research challenges for the aforementioned structural systems. First, the motivation and the basic principles, as well as methodology of DRSRS system, are briefly reviewed. Then, the seismic behaviors of several current different types of DRSRS systems including the RSE, RCRC, and SCSRS systems are overviewed in detail. Finally, some current research challenges and the recommendations for future studies for DRSRS system are summarized and discussed.

\section{Motivation of High Performance DRSRS Systems}

For the sake of protecting the lives of the occupants, structures are typically designed for "life-safety" performance according to the most modern building codes and are expected to undergo significant structural or nonstructural damage referred as residual deformation during a severe earthquake. Repairing damaged structures with large residual deformation is expensive and time-consuming, even the structures with significant severe residual deformation have to be demolished due to the high cost.

Since the 1990s, the performance-based design method has been adopted by most engineers and researchers in the world, and this designed method has been developed three generations [10-12]. It is expected that the structure designed according to the performance-based design method can have prospective seismic behaviors to withstand the possible earthquake and have the safety to protect the lives of the occupants and that the seismic damage of the structure due to the possible earthquake can be controlled within the expectant degree. The principle of "undamaged under minor earthquake, repairable under moderate earthquake, and uncollapsed under large earthquake" proposed by the Chinese seismic code and Japanese seismic code is similar to the purpose of the performance-based design method. However, due to the uncertainty of the earthquake, the structures possibly suffer from larger earthquake than the predicted level, causing the seismic damage of structure to be more serious than the predicted damage. The structures with severe seismic damage bring a big difficulty to the repairing of building and the rehabilitation of the society.

The reconstruction after the Kobe Earthquake lasted 10 years and the money for reconstruction reached up to 145 billion USD [13]. After the Great East Japan Earthquake in 2011, the first time budget fund applied from Japan government for the reconstruction is up to 35 billion USD, which could not satisfy the need of reconstruction; this also caused a heavy burden on the Japanese economy [14]. The estimated cost of rebuilding after the earthquake occurred in Christchurch, New Zealand, in 2011 is 28 billion USD, which is approximately $20 \%$ GDP of New Zealand without including economic losses associated with business downtime, and the Christchurch reconstruction is still underway until 2014 [15, 16]. Therefore, the importance of minimizing the residual deformation to make the repairing of structure easier was pointed out $[17,18]$.

It is understood that engineering structures with large residual deformation are harm to the sustainable and resilient city because it is necessary to consume lots of time and social wealth for reconstruction after the earthquake. Consequently, there is a consensus to develop a new generation of the seismic resisting structural system to withstand the earthquake, which has a strong resilient capacity and very small structural damage after the earthquake.

\section{Basic Principles and Methodology of High Performance DRSRS Systems}

In order to understand how to control the damage of structure, it is necessary to understand the mechanism of damage of the conventional seismic resisting structure. The conventional approach to earthquake resistant design of buildings depends upon providing the building with strength, stiffness, and inelastic deformation capacity. Figure 1 schematically shows the seismic performances of the conventional seismic structural system.

As shown in Figure 1(a), conventional seismic structural system satisfies the demand of deformation through plastic hinges at the bottoms of the column and the ends of the beam. The conventional seismic resisting structural system undertakes two responsibilities simultaneously: (1) resisting the earthquake force through strong stiffness; (2) dissipating the earthquake energy through inelastic buckling or yielding of longitudinal bars and crushing of concrete at compression zone, as shown in Figure 1(b); this leads to the hysteretic loop of the conventional seismic resisting system is plump, shown as in Figure 1(c). However, the plump hysteretic loop indicates that severe damage and large residual drift are possible after 


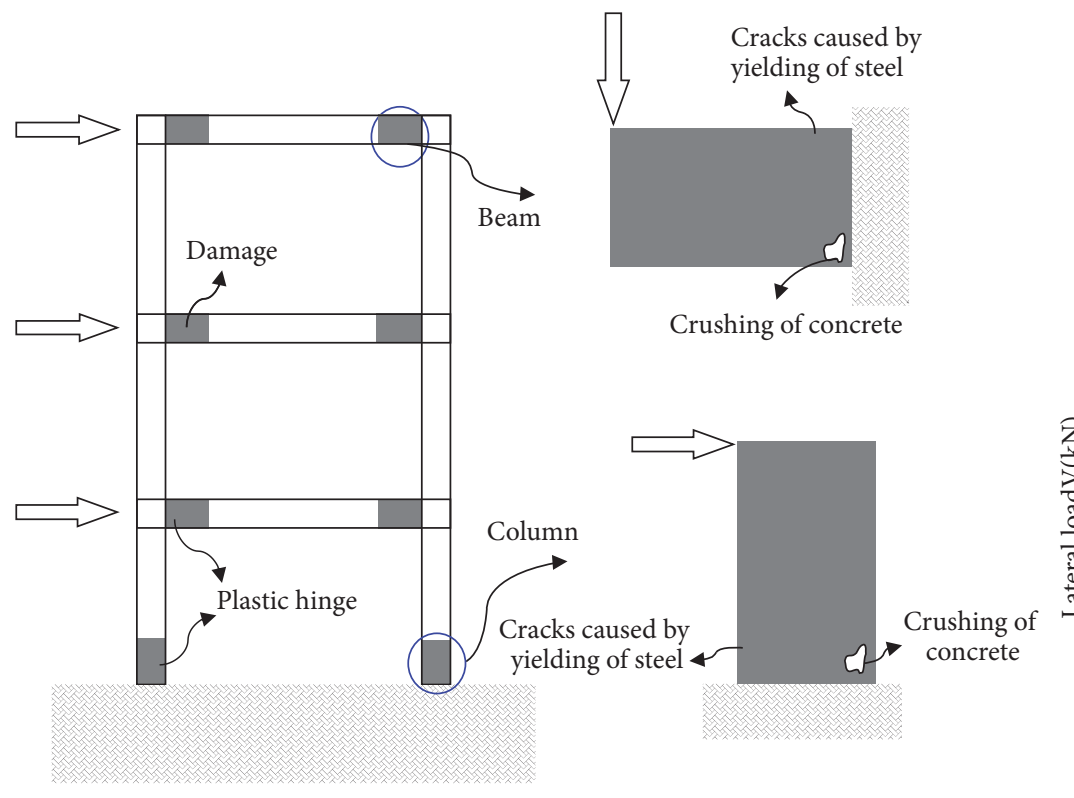

(a)

(b)

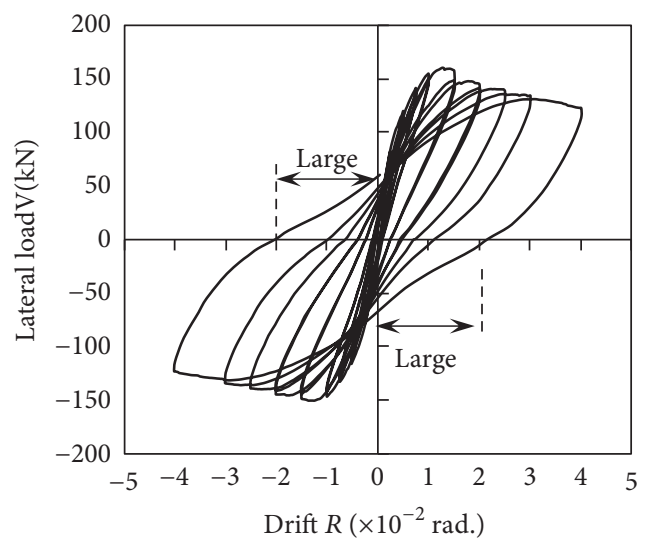

(c)

FIGURE 1: Seismic performance of conventional seismic structural system: (a) seismic resisting structural frame; (b) damage of structural element; (c) hysteretic curve of lateral force (adopted from [19], copyright 2014 JCI).

the lateral seismic force is removed, shown as in Figure 1(c). The stations above indicate that controlling the damage of a structure should emphasize the interface of two structural members and the plastic hinge zones.

To reduce the damage of conventional seismic resisting structural system, more advanced techniques are not to strengthen the structure, but to soften the earthquakegenerated forces acting upon it. Among the most important advanced techniques of earthquake resistant design and construction are (1) energy dissipation devices and (2) base isolation. In particular, the base-isolated structure reduces the damage through a series of bearing pads which are placed between the building and the foundation. The foundation and the upper building are separated, and the connection between them is weakened. The bearing pads dissipate the most seismic energy, while the base-isolated structure itself escapes the deformation and damage.

The principle of weakening the connection between upper structure and the foundation is adopted into developing the rocking structural system. The upper structurefoundation intersection of the rocking structure could undertake the compressive force but could not bear the tensile force. A certain uplift (rocking) is promised at the upper structurefoundation intersection under the lateral earthquake load; however, the upper structure does not bear the bending deformation, as shown in Figure 2(a). The weight of structure returns the whole structure back to the vertical location without or with little residual deformation. The posttensioned tendons or strands are included to provide the restoring force for the rocking structure, as shown in Figure 2(b). Figure 2 implies that the damage of both two structures is eliminated by the rocking weakening behavior at the intersection; however, the resilient forces are different. The self-centering forces of structural systems shown in Figures 2(a) and 2(b) are provided by the uncontrolled gravity of structure and the controlled recovery force of tendon or strand, respectively. In order to distinguish them, two types of structures shown in Figures 2(a) and 2(b) are called rocking seismic resisting structural (RSRS) system and self-centering seismic resisting structural (SCSRS) system in this paper, respectively.

On the other hand, the RSE is based on the mechanism that the structure fails in the relative weak location under loading. The RSE designed at the relative weakening location can be easily replaced after the earthquake; as a result, the entire structure can be quickly rehabilitated and desterilized.

In order to enhance the seismic energy dissipation capacity, types of energy dissipation devices and dampers, as well as fuse sections, are included the DRSRS systems including the RSE and RSRS system as well as the SCSRS system.

\section{Replaceable Structural Elements}

As is well known, there is somehow an essential mechanism that the structure failed at the weakening structural elements under loading condition. Consequently, it is possible that the structure failed at one or some artificial weakening structural elements which are called RSE. In general, RSE is used by mechanics; application in structural engineering is limited and focuses on the steel structure and bridge structure as well as the precast structural system until now.

4.1. Bridge Engineering Structure. A new concept [20] for bridge tower designs in seismic zones using sacrificial inelastic shear link schemes was adopted by TY Lin International 


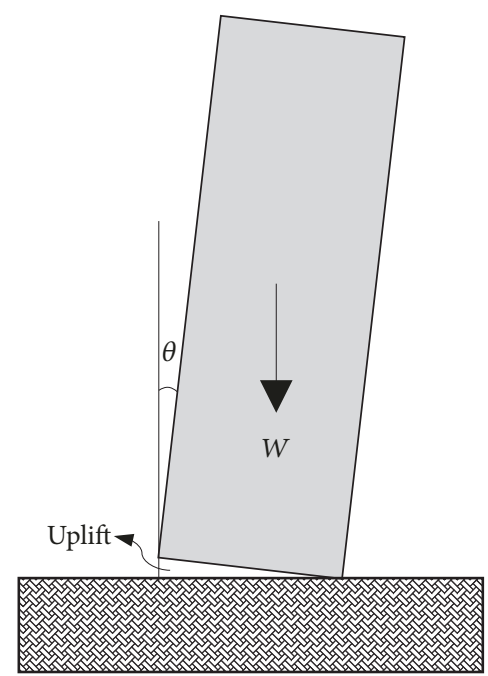

(a)

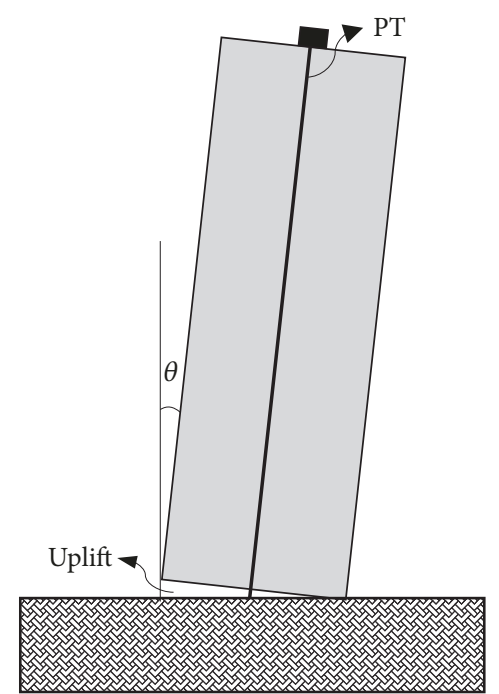

(b)

FIGURE 2: The principles of RSS system and SCS system: (a) DRSRS system; (b) SCSRS system.

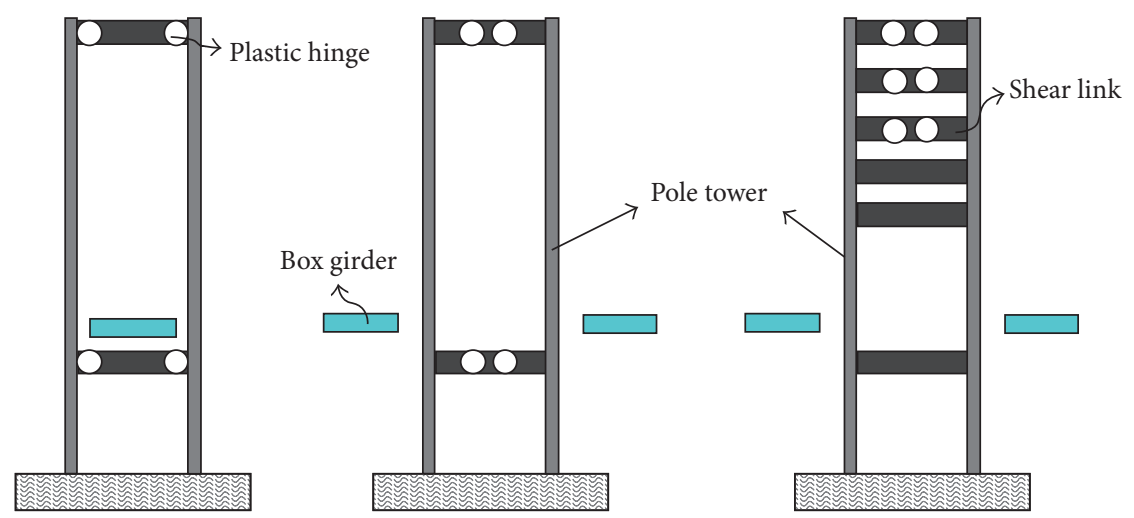

FIgURE 3: Concept of shear links of San Francisco-Oakland Bay Bridge (adopted from [20], copyright 2004 ASCE).

in 2000, shown in Figure 3. The sacrificial inelastic shear link could enable the new San Francisco-Oakland Bay Bridge (SFOBB) signature tower shafts to remain elastic during large seismic events and capable of carrying the large axial loads delivered by the suspension cables. In addition, the shear links are bolted to the tower shafts; therefore, the links are replaceable if required after large seismic events. It was shown that the inelastic tower links could be used to tune the dynamic response of bridge towers in regions of high seismicity through global seismic time history analysis [33].

4.2. Coupling Beam of Shear Wall System. The RSE design philosophy is most applied to coupling beam between wall systems. Fortney et al. firstly proposed a new type of fuse coupling beam (FCB) $[21,22]$, as shown in Figure 4. It is assumed that all inelastic deformations will be concentrated in the middle section (fuse section) of the beam such that the two outer steel beam parts could be protected. The fuse section is connected to the outer steel beam section via the flange splice plates at top and bottom flange and web splice plate, as well as slip critical bolted connections. The compared experimental results showed that FCB led to early energy dissipation and lower stiffness relative to the typical steel coupling beam (SCB); nevertheless, postdamage repair/replacement difficulties and expenses are minimized [22]. Additionally, in order to enhance the stiffness and energy absorption capacity and to reduce construction difficulties of RSE, some innovated alternative schemes were performed $[34,35]$.

$\mathrm{Lu}$ et al. proposed three types of steel coupling beams for the shear wall structural system with replaceable fuse $[23,43]$, as shown in Figure 5. Type I fuse is a steel I-beam whose web has a diamond-shaped hole; type II fuse is two webs of the steel I-beam, filled with lead between the webs; type III is two round steel tubes, filled with lead in the tube. The experimental results indicated that the shear capacities of shear wall systems with replaceable fuses were close to that of the conventional shear wall system. Moreover, the inelastic deformation and damage of specimens were concentrated in the fuse section as expected $[44,45]$. In order to reduce the damage at the bottom of the shear wall, new replaceable foot 


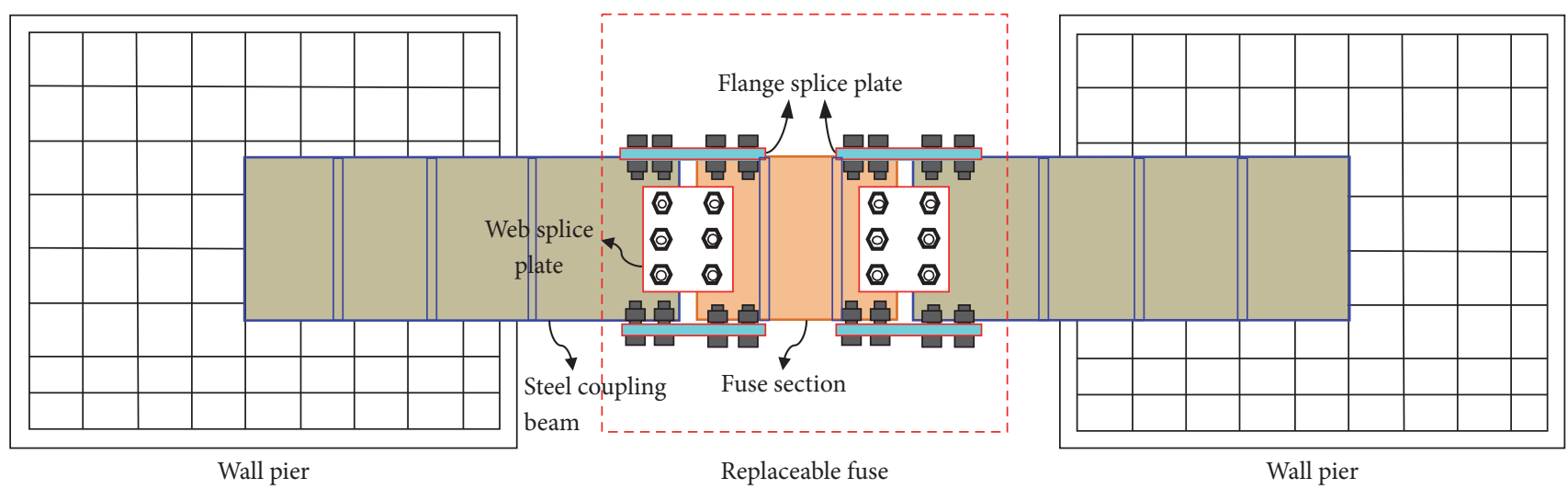

FIGURE 4: Details of replaceable fuse steel coupling beam (adopted from [21, 22], copyright 2006, 2007 ASCE).

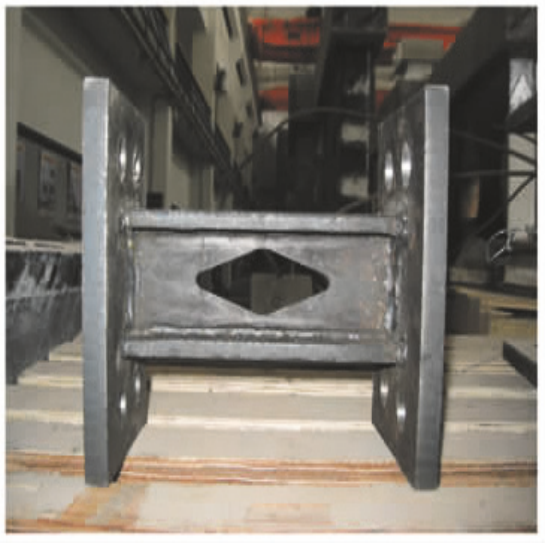

(a)

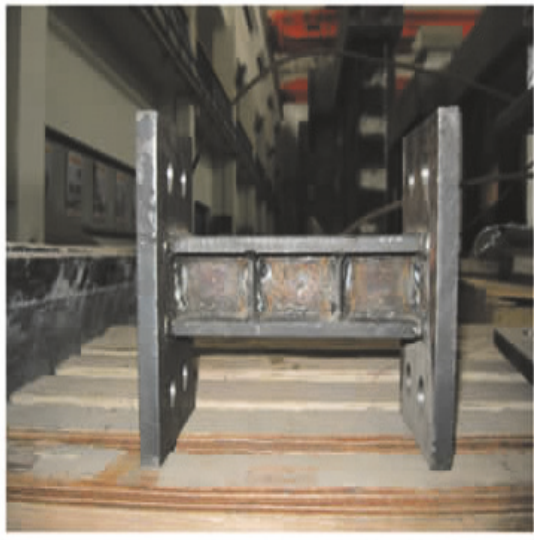

(b)

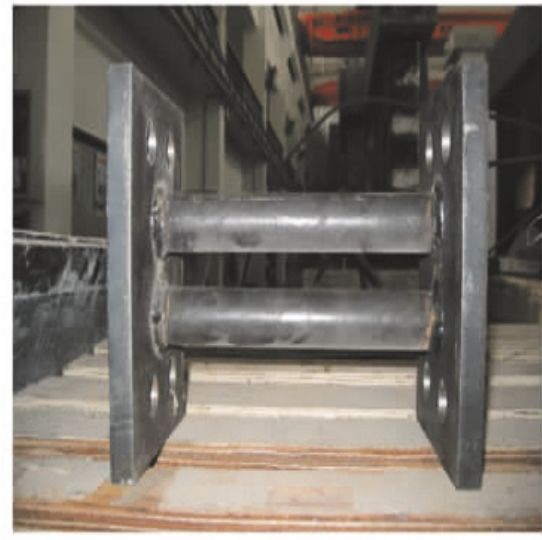

(c)

Figure 5: The new replaceable coupling beams proposed by Lu: (a) type I; (b) type II; (c) type III. (adopted from [23], copyright 2013 Journal of Earthquake Engineering and Engineering Vibration).

parts for the shear wall were proposed [46]; it was experimentally revealed that the proposed foot parts wall could greatly minimize the damage at the bottom of the shear wall. Similar to the replaceable coupling beam type III proposed by Deng et al., replaceable steel truss coupling beams were developed and used into the shear wall structural system $[47,48]$.

The replaceable steel coupling beam (RSCB) shown as in Figure 6 was proposed by Ji et al. [24]. The cyclic behavior of short shear link was experimentally studied in detail [49]. Furthermore, the scheme of proposed RSCB was further innovated and the seismic behaviors were experimentally numerically studied $[24,50]$. The test results showed that the wall systems with shear link had a good shear strength and large inelastic rotation capacity; in particular, the damaged shear link was replaced within very short time [50].

The replaceable steel coupling beams (RSCB) aforementioned can be taken as shear links with weakening section relative to protected normal beam segment and shear walls; the earthquake energy is dissipated by RSCB through inelastic deformation. If the RSCB is attached to a damper, more earthquake energy can be dissipated, and the shear wall can be preferably protected. Chuang et al. used a friction damper in the replaceable coupling beam of shear wall to enhance the earthquake energy dissipation capacity [25]. Figure 7 shows the configuration of the proposed friction damper which consists of two sets of an I-beam, a gusset plate, a steel plate for connection, and a brass plate used as the friction material, as shown in Figures 7(a) and 7(b). The earthquake energy is dissipated by the friction damper through the vertical deformation of the slot hole, shown as in Figure 7(c).

Teng et al. developed a mild metallic beam damper for coupled shear wall system [26], as shown in Figure 8; the proposed beam damper is a steel plate with low yielding strength and rectangular column holes. The experimental results showed that the global buckling in plane occurred under loading, and the damper behaved with great energy dissipation capacity [26]. The pseudodynamic test result indicated that the proposed mild metallic beam damper could reduce the seismic response of shear wall system and make the earthquake energy larger [58].

Mao et al. proposed a type of shape memory alloy damper (SMA) to dissipate the earthquake energy of coupling beam in RC frame-shear wall structural system [27]; the assembly 


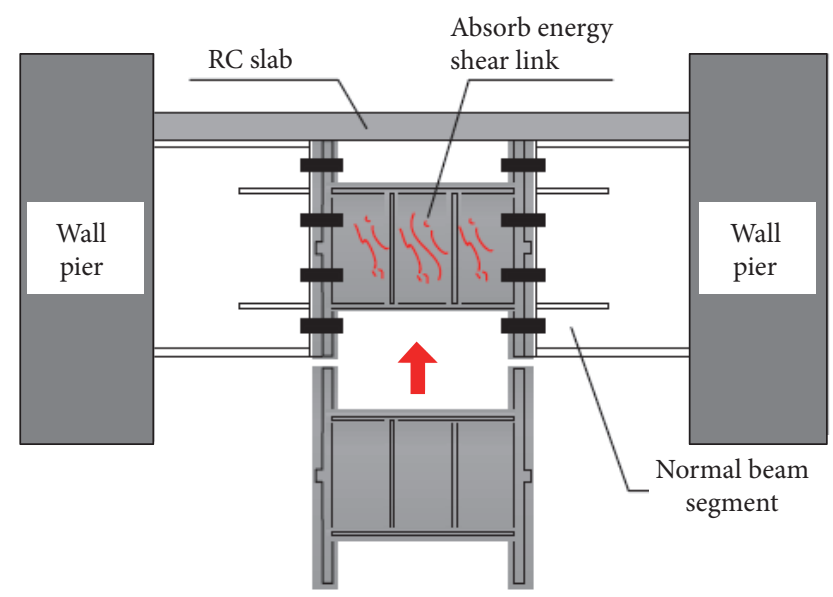

Replaceable shear link

FiguRE 6: Replaceable steel coupling beam (RSCB) (adopted from [24], copyright 2016 Engineering Mechanics).

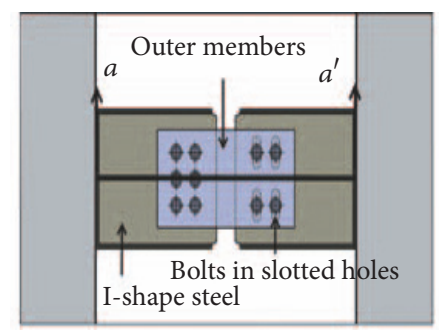

(a)

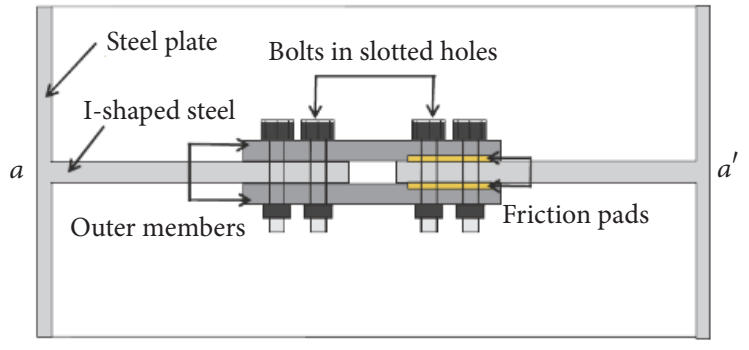

(b)

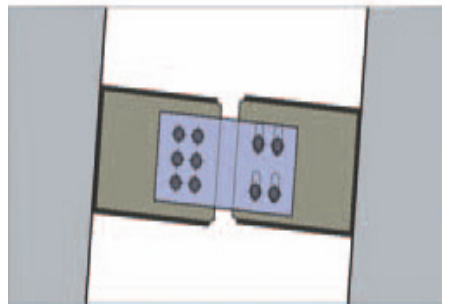

(c)

FIGURE 7: Slot bolt-type connection installed between coupled beams. (a) Elevation. (b) Sectional view. (c) Slip of slot bolt-type connection by the flexural deformation of walls (adopted from [25], copyright 2009 Structural Design Tall Spectral Building).

of SMA is schematically shown in Figure 9. The SMA damper contains four steel components (assembly parts I-IV) and two groups of SMA wires (group A and B); the earthquake energy is dissipated through tension of SMA wires located around the ears on part II and III (or part II and IV) when relative vertical displacement occurs between cantilever shear wall ends.

Kumagai et al. developed a type of RC shear wall structural system with coupling beam damper [28, 29], as shown in Figure 10. The coupling beam damper is a rectangular steel shear plate with a low yielding point, which is connected to the steel beam embedded in shear walls. Experimental result showed that the proposed coupling beam damper behaved with stable hysteretic response, and the load carrying capacity did not deteriorate up to $1 / 20 \mathrm{drift}$ angle. So far, there were nine building structures adopting the proposed coupling beam damper [59].

A new viscoelastic coupling damper (VCD) device was developed by Lyons et al. [30] to use into the coupled wall of the high-rise building. As shown in Figure 11, the VCD consists of multiple layers of viscoelastic (VE) material, placed between layers of steel plate which are anchored at alternating ends to the coupled $\mathrm{RC}$ walls using a number of different connection details. In addition, ductile "fuse" mechanism can be added in series with the VE material. The experimental result validated that the VE material exhibited stable hysteretic behavior under the loading conditions that are expected in high-rise buildings under wind and earthquake loading. The full-scale test results also demonstrated the targeted viscoelastic response during the wind and lowlevel earthquake loading and the targeted viscoelastic-plastic response for extreme earthquakes, where the response is a combination of the $\mathrm{VE}$ response and the nonlinear behavior of the structural fuses [60].

Kim et al. proposed a hybrid energy dissipative device (HEDD) applicable to RC shear wall structural system which consists of U-shaped steel plates and high damping rubbers $[31,32]$; the HEDD is schematically shown in Figure 12 . The high damping rubber damper placed between the casings (Casing 1 and Casing 2) is designed to accommodate shear deformation when the rotation of building occurs. Experimental investigations were conducted to validate the excellent seismic performances of RC shear walls connected by hybrid energy dissipative coupling beams.

Kurama and Shen proposed unbonded posttensioned hybrid coupled wall for shear wall structural system [36], 


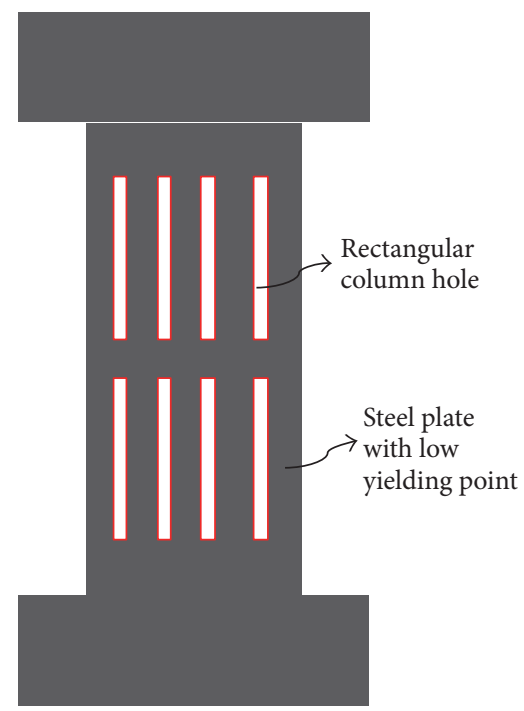

Figure 8: Elevation of mild metallic damper (adopted from [26], copyright 2010 Journal of Building Structures).

shown as in Figure 13; reinforced concrete walls are coupled using steel beams and unbonded posttensioning, without embedding the beams into the walls. The beam-to-wall connection regions include top and bottom angles bolted to the beam flanges and to steel plates embedded in the walls (using welded headed studs); the angles are to yield and provide energy dissipation during an earthquake and resist sliding of the beams along the beam-to-wall connections. The seismic behavior of the proposed unbonded posttensioned hybrid coupled wall was experimentally studied in detail $[67,68]$. The nonlinear load-deformation behavior of proposed hybrid coupled wall system was analyzed, and a simple design method based on fiber elements to estimate the nonlinear load-deformation was proposed. The results indicated that unbonded posttensioned steel coupling beams with initial stiffness similar to embedded steel beams can be designed to provide stable levels of coupling without experiencing significant damage over large nonlinear cyclic deformations [69, $70]$, and the design approach was proposed for the unbonded posttensioned hybrid coupled shear wall structural system [71].

4.3. Frame Structural System. In order to prevent damage to columns or infill walls and to minimize life-safety hazards during potentially earthquakes, Aliaari et al. developed a seismic infill wall isolator subframe (SIWIS) system [37, 72, 73], shown as in Figure 14. The SIWIS system consists of two vertical and one horizontal sandwiched light-gauge steel studs with "rigid-brittle" elements in the vertical members. As a "sacrificial" component or a "structural fuse" to protect the infill wall and frame from failure, the SIWIS is designed to allow infill wall-frame interaction under wind loading and minor-to-moderate earthquakes for reduced building drift but to disengage them under damaging events. The seismic performances of SIWIS system were experimentally investigated in detail $[37,74]$ and analyzed using nonlinear finite element models [75, 76]. Analysis results showed that the concept of SIWIS system works in providing initially high stiffness followed by an isolation of infill wall from interaction with the confining frame. Practical design guidelines are proposed, and the result of the study demonstrates that the proposed isolation system has merits and can potentially improve the seismic performance of masonry infill walls by protecting the infill wall and the frame from damage due to their interaction [77].

\section{Rocking Seismic Resisting Structural Systems}

In 1963 the first time analysis of the rocking motion of structures was performed by Housner who found that several golf-ball-on-a-tee types of elevated water tanks survived the ground shaking due to the effect of uplift despite the appearance of instability; on the other hand, much more stableappearing reinforced concrete, elevated water tanks were severely damaged during the Chilean earthquakes of May 1960 [81].

Since the 1970s, the principle of rocking motion of structure was largely applied to research on the seismic resisting structural system. Hukelbridge and Clough studied the effects of allowing column uplift in steel building frames on seismic response under severe seismic loading; the table test results indicated that allowing column uplift was shown for this frame to significantly reduce both the seismic loading and ductility demand $[82,83]$. Priestley et al. verified the mechanism of energy dissipation of rocking structural system through table test and proposed a simple design method for assessing maximum rocking displacements, using equivalent elastic characteristics and a response-spectra approach [84]. Basically, the analysis of the seismic response of rocking structural system under the earthquake lateral loading was gradually deeply studied before the 1980s [85-88].

After completing the theoretical mechanism analysis of the seismic response of rocking structural system, the experimental studies on types of engineering structural systems such as bridge engineering and building structures were started from the 1990s. The methodologies of rocking structural system were through not only softening the connection between structure and foundation but softening the connection between structural elements such as beam-column joint.

5.1. Rocking Bridge Pier Structure. Aslam et al. studied the rocking motion of a major pier in the bridge, a semirigid seismic connection was used at the base of the pier and the rocking of the pier was permitted to take place during the future major earthquakes $[87,88]$. Priestley et al. proposed rocking bridge pier as a strengthened design and seismic design scheme of bridge engineering [89]. Mander and Cheng developed a new paradigm called Damage Avoidance Design (DAD), in which the bridge piers is free to rock under large lateral loads such that damage is avoided by the special detailing of the connections [90]. Mashal et al. used dissipative controlled rocking (DCR) systems with types of external and internal dissipation devices into Accelerated Bridge 


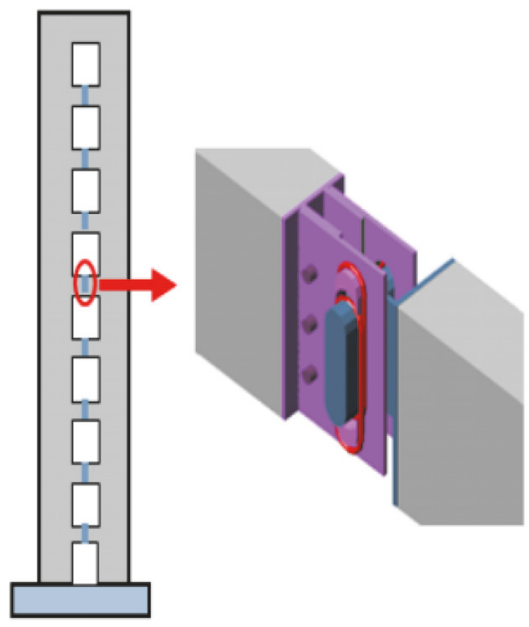

(a)

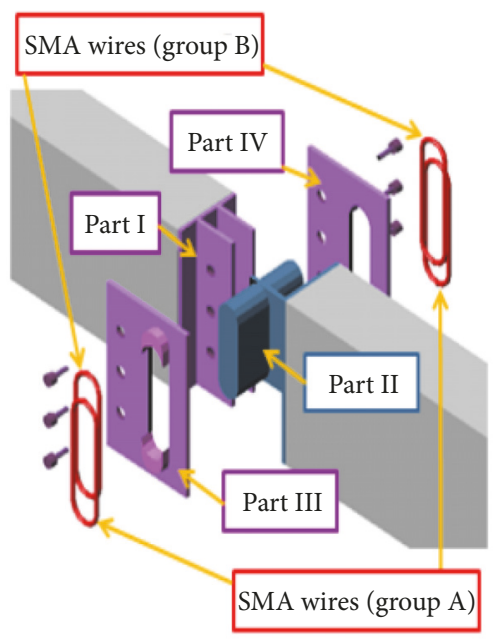

(b)

FIGURE 9: The location and assembly parts of the SMA damper in the coupling beam: (a) location of the SMA damper; (b) assembly parts of the damper (adopted from [27], copyright 2012 WCEE).

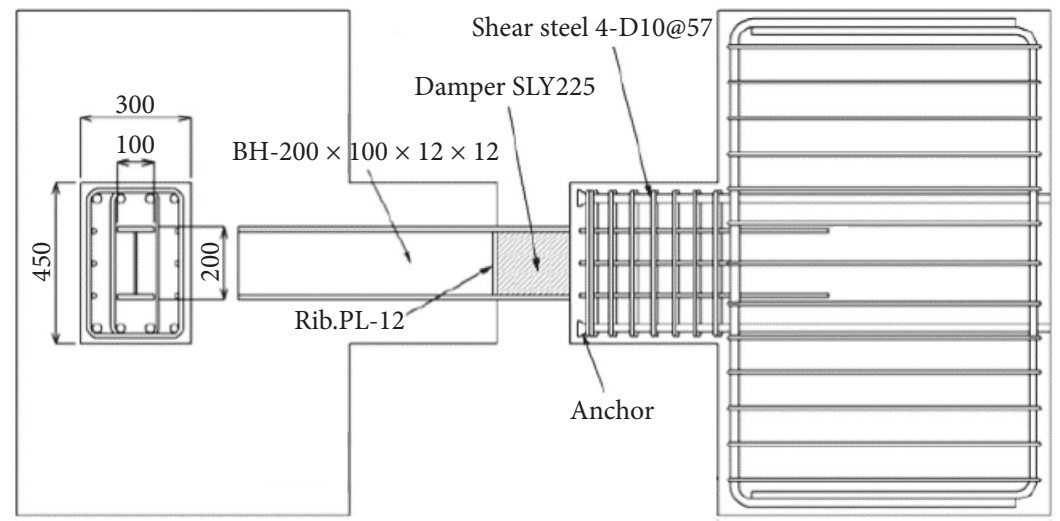

Figure 10: Dimensions and reinforcement of replaceable coupling beams (adopted from [28, 29], copyright 2009 AIJ and 2010 Tokyo University).

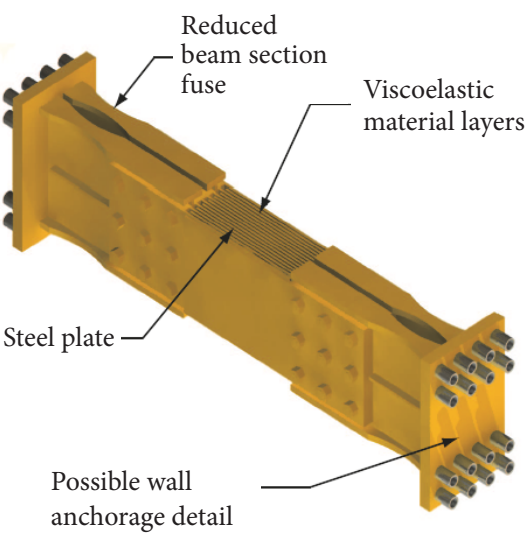

(a)

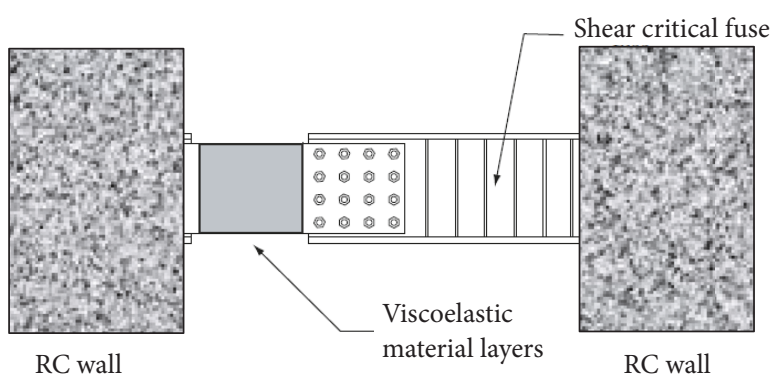

(b)

FIGURE 11: RC coupled wall high-rise building with viscoelastic coupling dampers: (a) viscoelastic coupling damper (VCD); (b) alternative design using VCD for prototype structure (adopted from [30], copyright 2012 WCEE). 


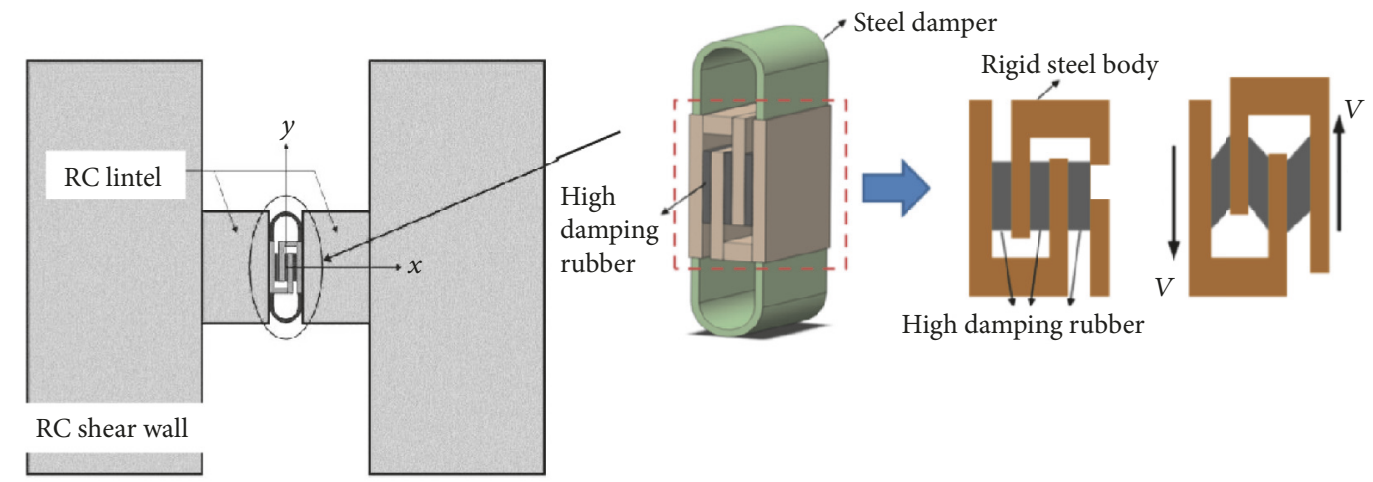

FIGURE 12: Schematic drawing of a hybrid damper embedded into a coupling beam connecting RC shear walls and the deformed shapes of a hybrid damper (adopted from [31, 32], copyright 2012, 15 WCEE).

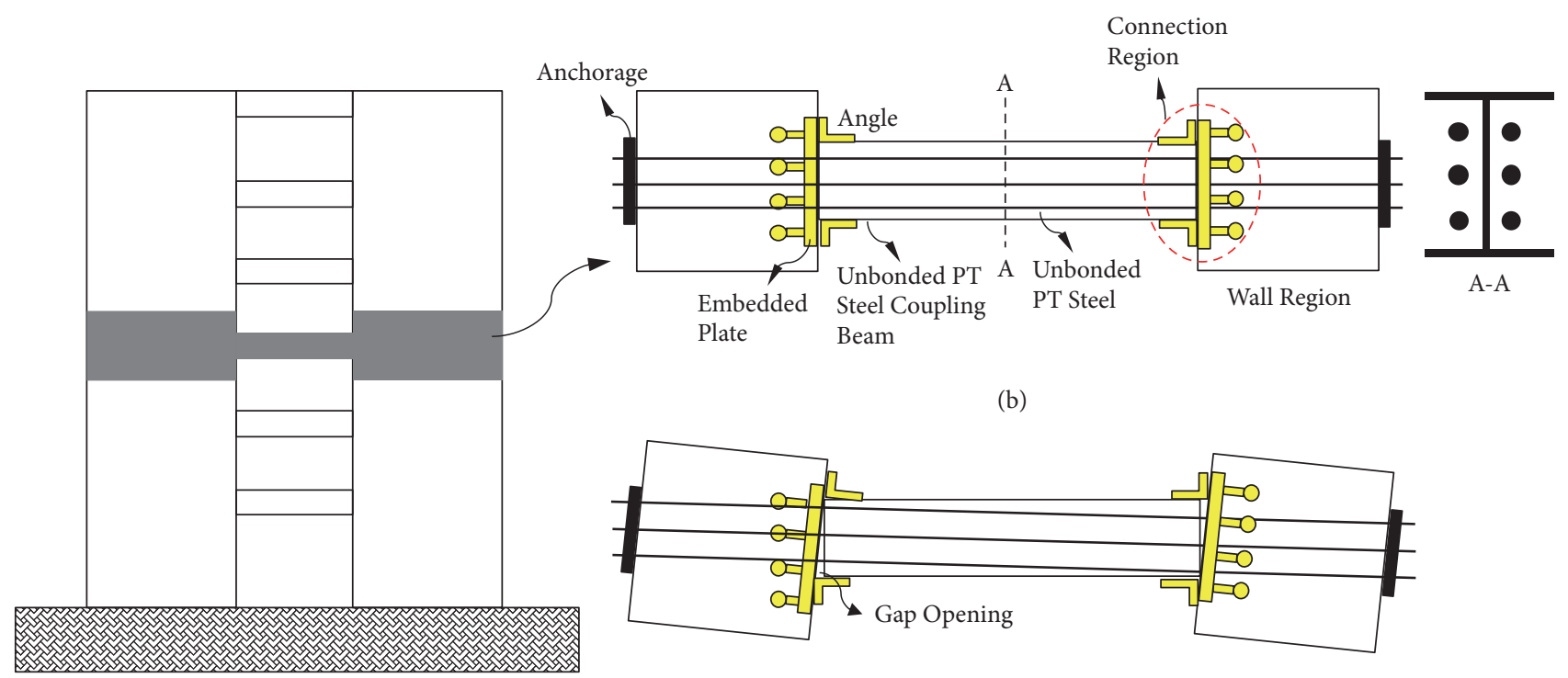

(a)

(c)

FIGURE 13: Unbonded posttensioned hybrid coupled wall subassemblage: (a) location of coupled beam; (b) elevation; (c) deformed shape (adopted from [36]).

Construction $(\mathrm{ABC})$ to enhance the seismic behavior of Accelerated Bridge Construction (ABC) structures [91].

5.2. Rocking Concrete Frame System. Roh used the "rocking columns," a type of double hinged gravity column or cracked base and top column which resists vertical loads with minimum or no lateral strength, to reduce the strength of the part of the lateral load resisting system (i.e., weaken the structure) for controlling the story accelerations [92]. Roh and Reinhorn firstly proposed a macroscopic analytical approach applicable for analysis of rocking column [93]. The proposed model is verified through the quasi-static cyclic of $1: 3$ scale rocking column and the IDARC2D computational model [94]. Subsequently, the seismic performance of a span prototype structure with the proposed rocking column and damper was analyzed; the results indicated that the proposed rocking column and damper could effectively reduce the seismic response of structure [93].
Cao et al. [95] developed a new type of connection to assemble the frame and concrete rocking walls; test results showed the rocking wall with the novel connections effectively controlled the interstory drift concentration and endowed the structure with a uniform deformation mode when subjected to different loading patterns.

5.3. Rocking Steel Frame System. Eatherton et al. of Stanford University experimentally investigated the seismic behaviors of controlled posttensioned rocking steel framed buildings with replaceable energy dissipation fuses [38]; the rocking steel framed building is as shown in Figure 15; the experimental results indicated that the proposed rocking steel frame exhibited excellent recovery properties, and the seismic energy dissipation and damage were concentrated in the replaceable fuse elements. Midorikawa et al. conducted the three-dimensional table test of posttensioned steel frame in $2009[96,97]$, and Ma et al. performed a table test of $2: 3$ 

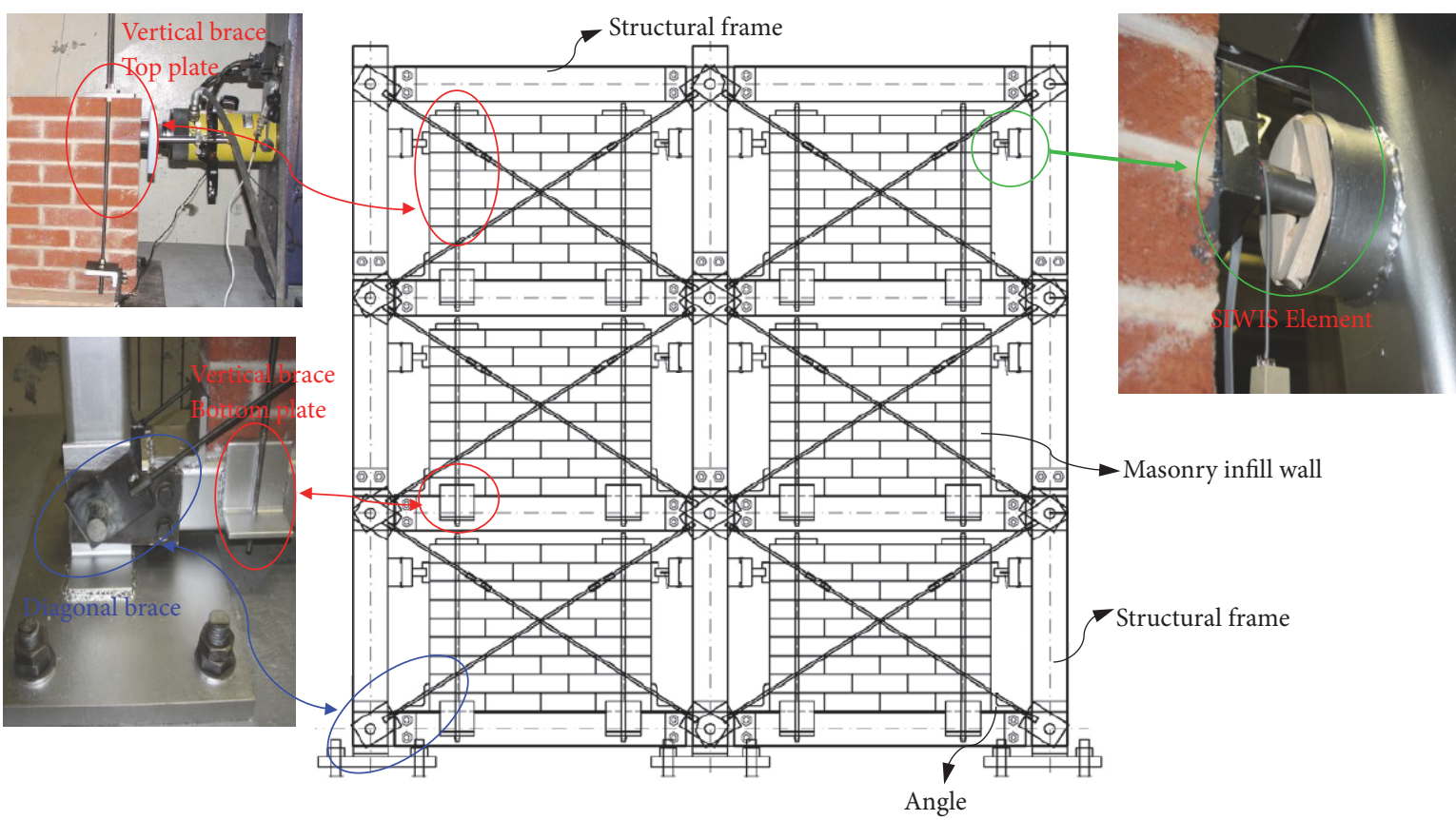

FIgURE 14: Schematic design of scaled two-bay three stories SIWIS frame (adopted from [37], copyright 2005 The Pennsylvania State University).
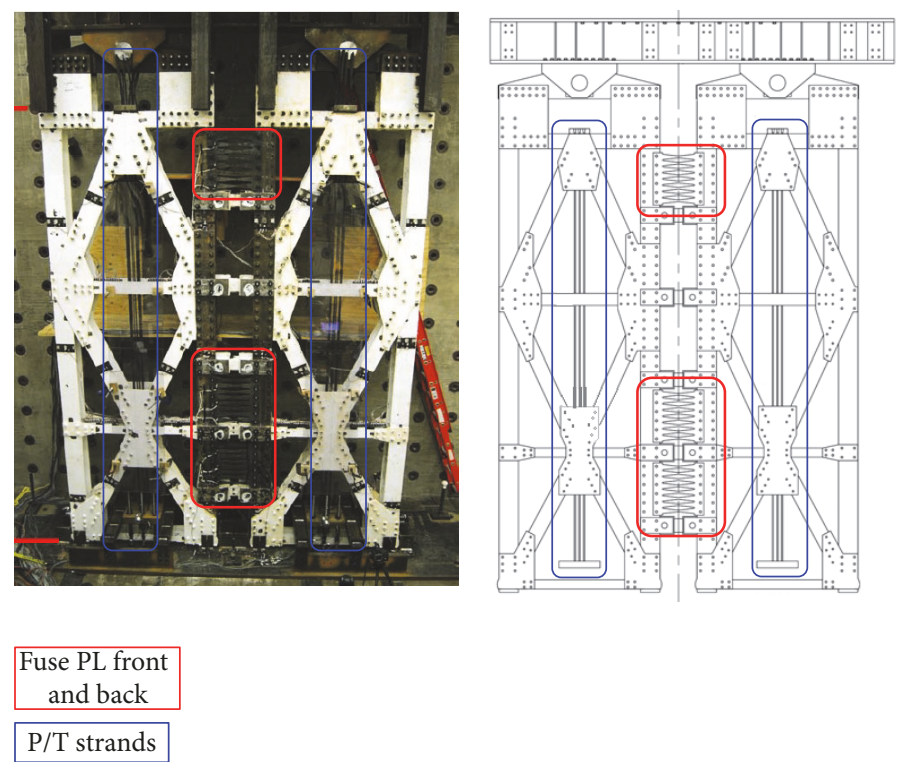

FIGURE 15: Posttensioned controlled rocking steel framed building with replaceable energy dissipation fuses (adopted from [38], copyright 2008 the 14th WCEE).

scale steel frame with controlled rocking column and earthquake energy dissipation device in E-Defense of Japan [98], Eatherton et al. also conducted similar test on this kind of steel frame [99].

5.4. Rocking Concrete Shear Wall System. Anderson studied the influence of the rocking of foundation on seismic response of the shear wall under seismic loading through the proposed computational model [100]. Gajan and Kutter
$[101,102]$ proposed that using rocking footings in place of, or in combination with, structural base isolation and energy dissipation devices improves the performance of the structure during seismic loading; results showed that a footing with large $A / A_{c}$ ratio ( $A$ is actual footing area, and $A_{c}$ is the area required to support the vertical and shear loads) possesses a well moment capacity that is insensitive to soil properties and suffers small permanent settlements [101]. The effects of static vertical factor of safety $\left(F_{\mathrm{SV}}\right)$ and the applied normalized 


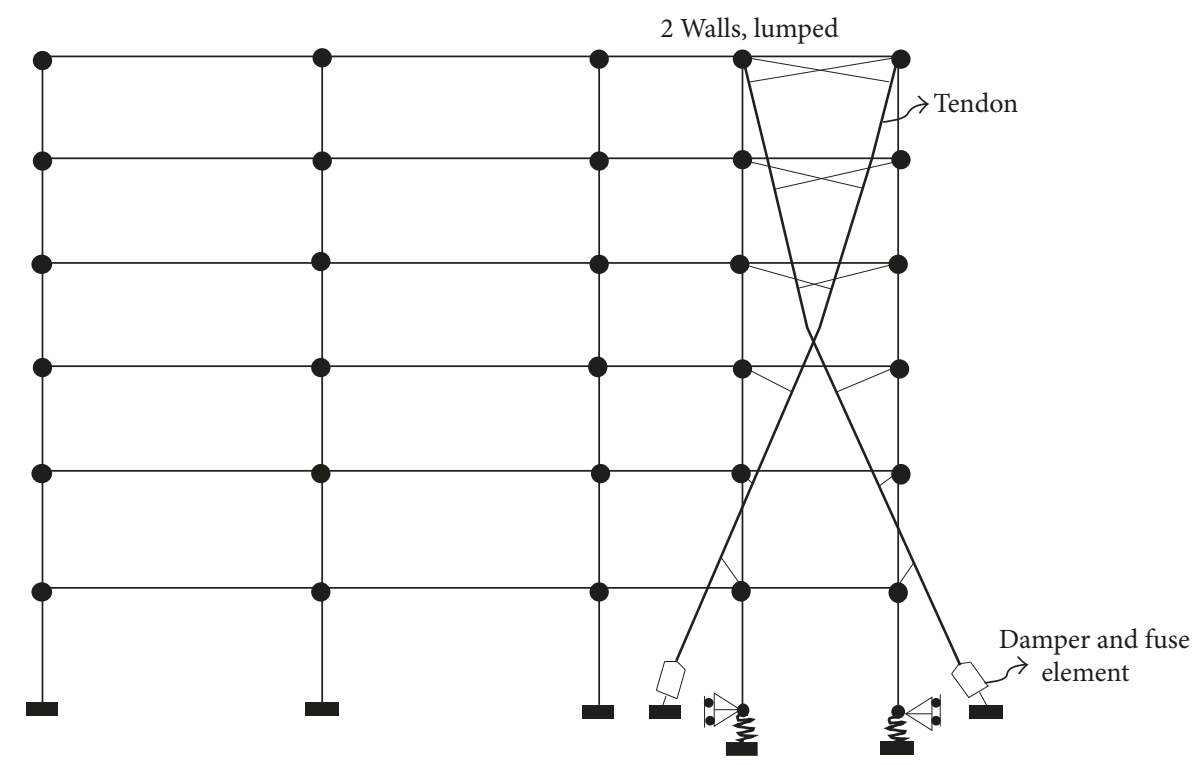

FIGURE 16: Scheme of a six-story rocking wall-frame building (adopted from [39], copyright 2004 Journal of Structural Engineering ASCE).

moment-to-shear ratio $(M / H L)$ at the footing-soil interface on footing-soil system behavior were analyzed; the results indicated that, for a particular $F_{\mathrm{SV}}$, footings with a large moment-to-shear ratio dissipate considerably more energy through rocking and suffer less permanent settlement than footings with a low moment-to-shear ratio [103].

Ajrab et al. [39] designed a six-story rocking wallframe building with various supplemental system configurations which include prestressed tendons and energy dissipation devices using performance-based design methodology, shown as in Figure 16. Seismic performance and response evaluation, using nonlinear time history analyses, suggests that desired performance levels, minor to no damage, can be achieved with added equivalent viscous damping, and the seismic response was not sensitive to the prestress level in tendons and to wall base width. However, this rocking wallframe building system is complicated such that it could not be extensively applied into constructions.

$\mathrm{Lu}$ [104] analyzed the influences of rocking wall and wallneutral axis as well as the $3 \mathrm{D}$ effect on the seismic response of RC wall-frame; the result indicated that uncontrolled wall rocking could cause beam-wall connection failure, leading to accelerated deterioration of the entire system. Pushover and dynamic time history analyses showed that by incorporating wall-neutral axis migration, more satisfactory prediction of the inelastic response of the wall-frame can be made. A systematic improvement of the wall-frame inelastic behavior can be achieved by involving the 3D effect.

Hitaka and Sakino [40] developed a new type of hybrid coupled wall (HCW) system which consists of rolled steel coupling beams, reinforced concrete (RC) wall piers, and concrete-filled tube (CFT) short columns, shown as in Figure 17. In this new system (HCW), the bases of the wall piers are connected to the base beams only through CFT short columns, and the yielding occurs in the coupling beams and the short columns. The experimental results indicated that the proposed HCW could fail in the expected location such as the coupling beam and CFT column with ductile behavior and large energy dissipation.

Wiebe and Christopoulos [105, 106] considered that structural forces of the base-rocking system can be increased significantly even when the base moment is limited because of higher mode effects. They suggested that higher mode effects may be substantially reduced by designing to allow rocking to occur at multiple locations over the height of a base-rocking system. The statistical study results showed that the bending moment envelope above the base of the wall is greatly reduced by providing multiple rocking sections, while the peak displacements do not increase in magnitude or in variability.

Mulligan et al. [107] analyzed a scaled semiactive rocking wall system using real-time, high-speed hybrid testing. The results showed that the semiactive devices are controlled to provide supplementary resistance only for the upward rocking motion of the wall, providing semiactive energy dissipation over half of each cycle and relying on radiation damping for the other half. Marriott et al. [108] proposed a displacement-based retrofit procedure based on targeting predefined performance criteria, such as joint shear and/or column curvature deformation limits; an extensive experimental program investigating the use of rocking wall systems to retrofit existing poorly detailed frame structures is promised.

Wada et al. [41] developed a retrofit system of prestressed concrete rocking walls and steel dampers to control the seismic damage mode and increase the strength and energy dissipating capacity of an 11-story steel reinforced concrete frame in Japan, shown as in Figure 18. The extensive nonlinear time analyzed results showed that the rocking system can significantly reduce both the seismic responses to different earthquake ground motions and their scattering.

5.5. Rocking Masonry Structural Wall System. Toranzo et al. used the principle of rocking wall system into confined 


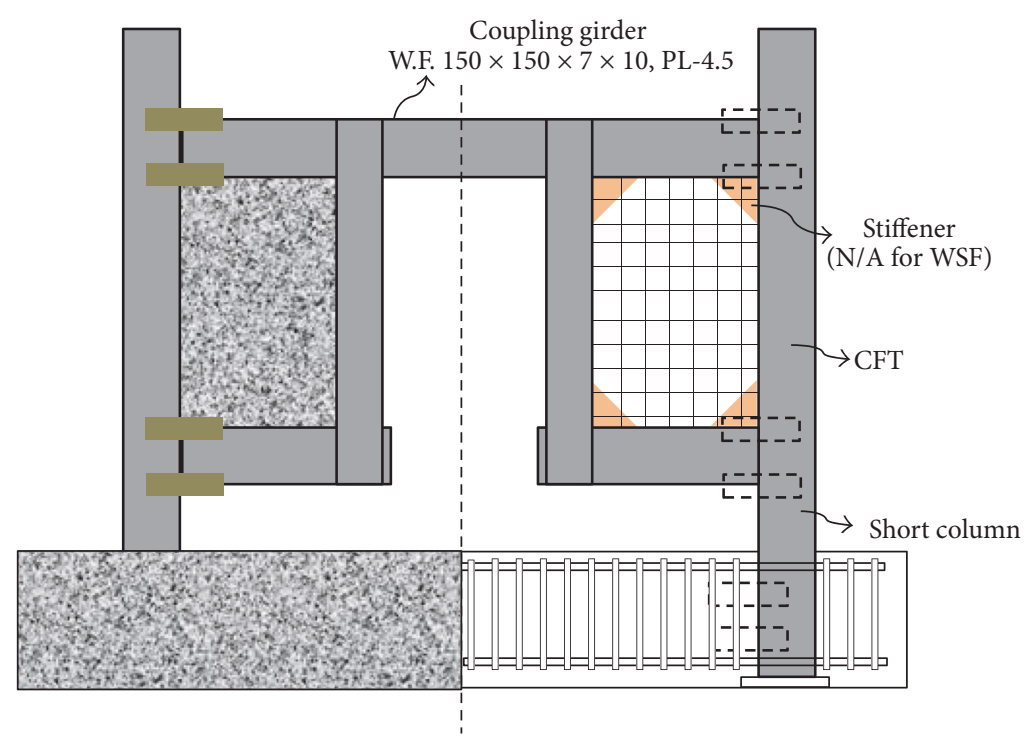

FIGURE 17: Rocking hybrid coupled wall (adopted from [40], copyright 2008 Earthquake Engineering and Structural Dynamics).

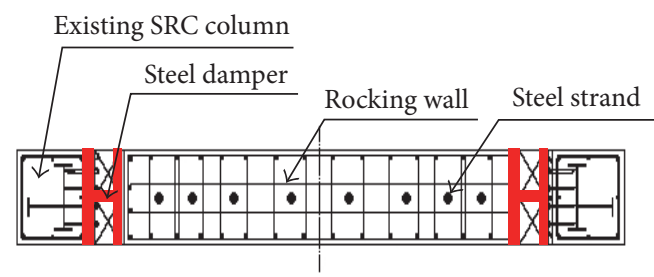

(a) Cross section

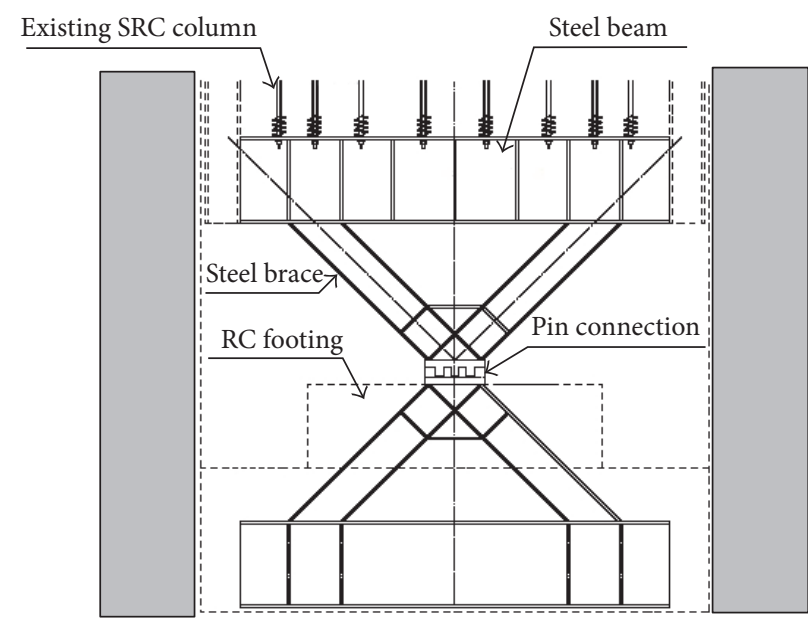

(b) Elevation

FIGURE 18: Structural retrofitting of rocking walls and steel dampers in Tokyo Institute of Technology (adopted from [41], copyright 2009 Applied Technology Council).

masonry structural system [42, 109-111], shown as in Figure 19. A shake table investigation was conducted to validate the concept of rocking walls as primary seismic systems; as the inherent damping of this system was low, a pair of supplemental steel hysteretic energy dissipating dampers were used at the base of the wall. The results indicated that with careful detailing, not only the damage was eliminated but the structure recenters itself following a large earthquake. They considered that the rocking wall concept can be extended to any rocking wall system.

5.6. Rocking Timber Structural System. Loo et al. [51] used a new concept in shear wall design into timber shear wall structure; the new concept involves the use of slip-friction connectors in lieu of traditional hold-down connectors [112], as shown in Figure 20. Slip-friction connectors, originally developed for the steel framing industry, rely on the mobilization of friction across steel plates to resist loading up to a predetermined threshold. Upon this threshold being exceeded, relative sliding between the steel plates allows the shear wall to be displaced in an inelastic manner. The numerical results suggested that slip-friction connectors hold the promise of being able to effectively protect sheathing, framing, and nail connections from excessive stresses and deformations during earthquake events of design level intensity or higher. Kishiki and Wada also utilized the philosophy of rocking into timber structural system and designed controlled wood wall structural system [113].

5.7. Rocking Core Wall System. The numerical results performed by Nielsen et al. [114] showed that the rocking core wall structural system possesses the recentering capacity due 


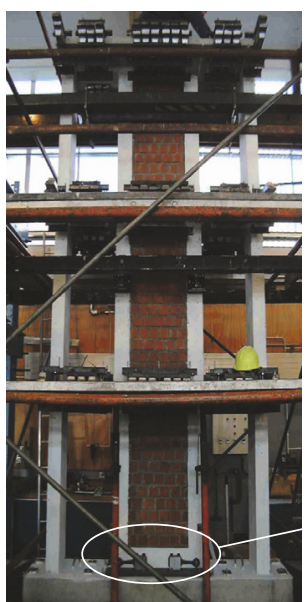

(a)

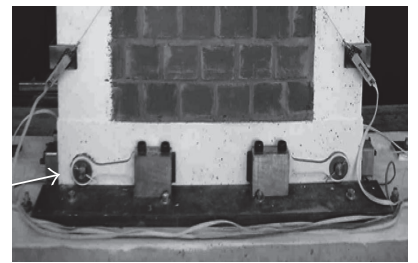

(b)
Figure 19: Three-story rocking confined masonry wall: (a) the elevation of the wall; (b) details of the energy dissipations (adopted from [42], copyright 2004, 13 WCEE).

to the effect of gravity, and the moment at the foundation of rocking core wall structural system is smaller by $30 \%$ than that of common core wall structural system having fixed foundation. Zhou et al. also obtained similar numerical results through compared analysis [115].

\section{Self-Centering Seismic Resisting Structural Systems}

On the basis of rocking structural system, the posttensioned tendons or strands are included into to externally provide a self-centering capacity to the structural system. The seismic resisting structural system with posttension is called selfcentering seismic resisting structural systems (SCSRSS).

6.1. Self-Centering RC Frame System. Priestley and Tao [52] developed a new type of self-centering precast concrete frame using partial debonded prestressing tendons in which the beam can rotate; the beam-column interface is shown as in Figure 21. Cheok and Lew [116] experimentally verified the above-mentioned self-centering precast concrete frame system.

In 1996, Priestley and MacRae developed precast concrete beam-column joint subassemblage with two ungrouted posttensioned tendons, shown in Figure 22, and performed experiment under cyclic reversal seismic load; the test results showed that energy absorption of the hysteretic response was larger than expected, and the residual displacements were negligible [53]. El-Sheikh et al. conducted pushover analysis and time history analysis of the developed precast concrete beam-column joint subassemblage [117]. Cai et al. [118] developed a kind of new self-centering posttensioned precast concrete beam-column connection in which prestressed bar was used to provide the self-centering capacity to structures and the steel angle clamped at the beam-column joint was used to dissipate the energy. Lu et al. [119] conducted a shake table test of a self-centering reinforced concrete frame; test results indicated that the designed reinforced concrete frame has good seismic performance and self-centering capacity subjected to earthquake ground motions; the self-centering structures can undergo large deformation with minor residual displacement after the strong earthquake excitations.

Morgen and Kurama developed a new type of friction damper for unbonded posttensioned precast concrete building moment frame structures in seismic regions, shown as in Figure 23; the proposed friction dampers were placed at beam-column joints. The compared test results showed that the dampers can provide a significant amount of supplemental energy dissipation at the beam ends, while the selfcentering capability of the structure is preserved [54].

6.2. Self-Centering RC Shear Wall System. Kurama et al. [55, 120-122] utilized unbonded posttensioned tendon or PT bar across horizontal joints to develop precast concrete wall, shown as in Figure 24; the unbonded posttensioned precast walls can soften and undergo large nonlinear lateral displacements with little damage, and the nonlinear behavior is primarily due to the opening of gaps along the horizontal joints; however, the energy dissipation capacity was low. Consequently, Kurama et al. [123, 124] used supplemental viscous damping to reduce the lateral drift of unbonded posttensioned precast concrete walls under earthquakes; the nonlinear dynamic time history analyses showed that the proposed energy dissipation system was effective in reducing the maximum roof drift to prevent significant damage to the walls, and Perez et al. $[125,126]$ also performed similar experiments and analysis. Smith et al. [127, 128] used the posttensioned tendon or PT bar technology into the hybrid wall which was constructed by stacking rectangular precast concrete wall panels across horizontal joints at the floor levels.

Holden et al. $[129,130]$ innovated the unbonded posttensioned precast concrete wall proposed by Kurama by adding longitudinal mild steel reinforcement crossing the joint between the walls and the foundation to enhance energy dissipation capacity. Marriott et al. [131] conducted shake table test of the proposed wall system with variable dampers; the test results showed that the proposed wall system had a great self-centering capacity. Sritharan et al. [56, 132] designed a jointed wall system in which two or more single precast walls designed with unbonded posttensioning are connected to each other with the help of special connectors along the vertical joints, as shown in Figure 25.

Panian et al. [133, 134] believed that the shear wall system with posttensioned prestressed tendon has a better economic benefit and seismic result. Furthermore, Stevenson et al. [135] had utilized posttensioned prestress steel bar into the design of shear walls in David Brower Center to resist the potential earthquake. Rahman and Sritharan [136] proposed the calculated model of a self-centering shear wall system. Pennucci et al. $[137,138]$ proposed the displacementbased design method of precast shear walls with additional dampers. Aaleti and Sritharan [139] proposed a simplified method to characterize the seismic responses of unbonded posttensioned precast wall systems. Erkmen and Schultz [140] performed a series of compared tests to study the self-centering capacity of precast walls. Twigden et al. [141] investigated a single posttensioned concrete wall subjected to 


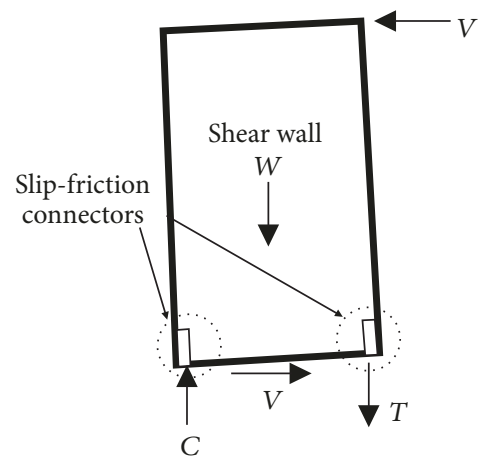

(a)

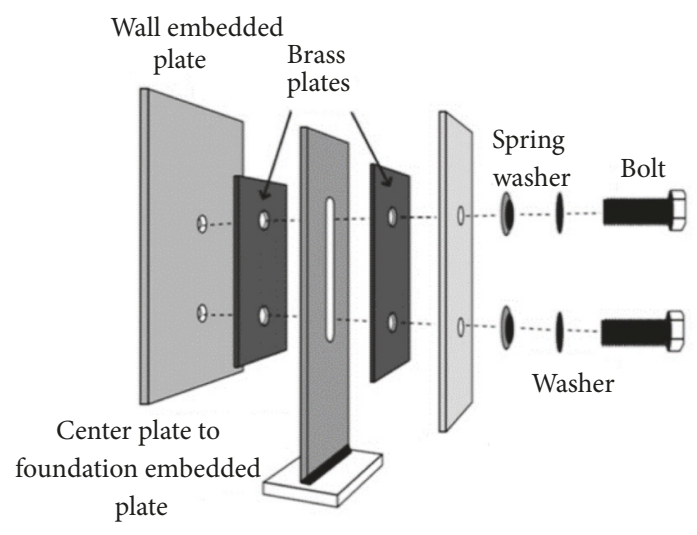

(b)

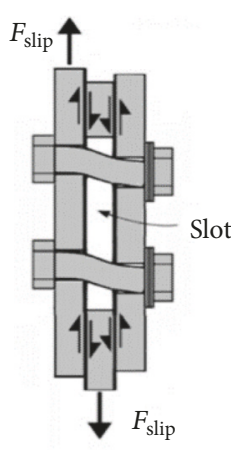

(c)

FIGURE 20: Slip-friction connectors with shear walls: (a) capping of lateral force on the shear wall; (b) connector assemblage for the precast concrete wall; (c) activated friction forces. (adopted from [51], copyright 2012 Engineering Structures).

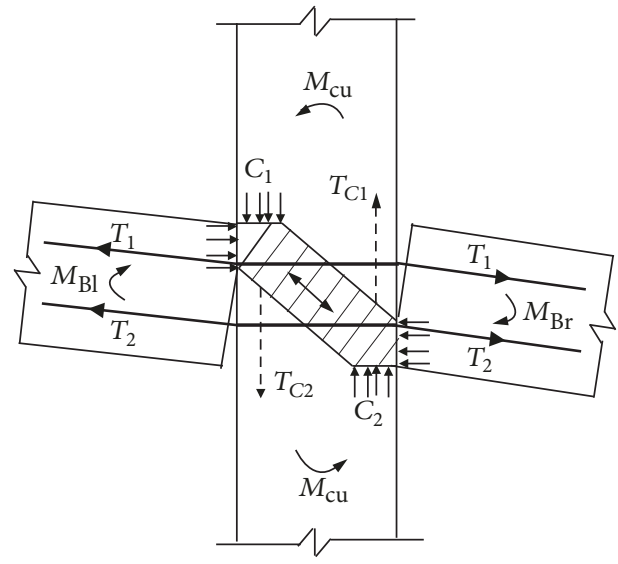

FIGURE 21: Beam-column connection with partially debonded prestressing tendons (adopted from [52], copyright 1993 PCI Journal).

pseudostatic cyclic loading, high-speed cyclic loading, free vibration, and dynamic forced-vibration testing.

6.3. Self-Centering Steel Frame System. Ricles et al. [57] of Lehigh University designed a new kind of steel beam-column interface connection of moment resisting frames (MRFs) with self-centering capacity using posttension high strength strands, shown as in Figure 26; the top and seat angles are added to provide energy dissipation and redundancy under seismic loading. This new type of connection has the following advantages: (1) field welding is not required; (2) the connection stiffness is similar to that of a welded connection; (3) the connection is self-centering; and (4) significant damage to the MRF is confined to the angles of the connection. Time history analysis results showed that the seismic performance of a posttensioned steel MRF subject to the earthquake records exceeds the performance of an MRF with typical welded connections subject to the same earthquake records. Consequently, many other researchers innovated this new type of steel beam-column connection $[66,142,143]$, Rojas et al. [144] added a posttensioned friction

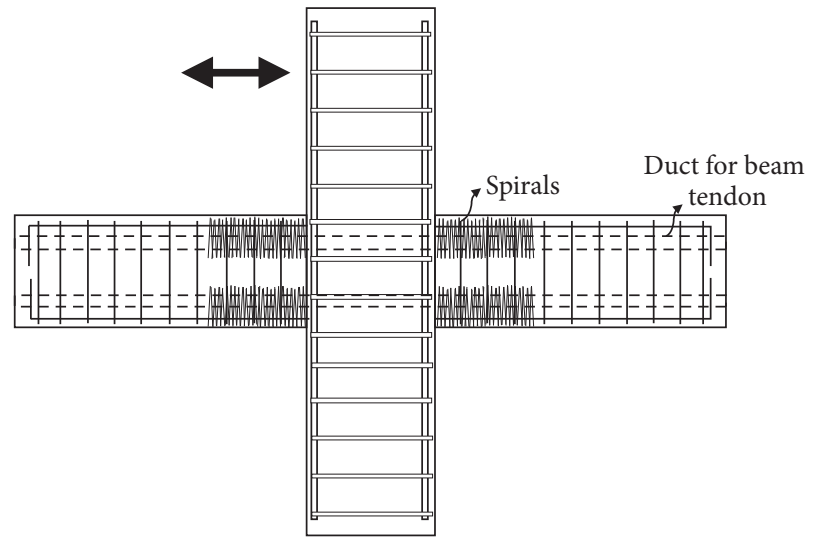

FIgURE 22: Precast concrete beam-column joint subassemblage with two ungrouted posttensioned tendons (adopted from [53], copyright 1996 PCI Journal).

damped connection (PFDC) into the above-mentioned steel beam-column connection to enhance the earthquake energy dissipation capacity.

Sause et al. [64, 145] developed self-centering moment resisting frames (SC-MRFs) and self-centering concentrically braced frame (SC-CBF) systems with the goal of providing adequate nonlinear drift capacity without significant damage or residual drift under the design basis earthquake. Both experimental results and analytical results indicated that all SC-MRFs and SC-CBF possess self-centering behavior, and no significant structural damage occurred. In order to use this new types of MRFs and SC-CBF into design and construction, the performance-based seismic design approach for PT steel frame systems was proposed; seismic performance levels, seismic input levels, structural limit states and capacities, and structural demands for PT frame systems were defined; the design objectives were outlined; design criteria were given; and a step-by-step design procedure was given [65].

Clayton [61] developed the self-centering steel plate shear wall (SC-SPSW) system, shown schematically in Figure 27, 


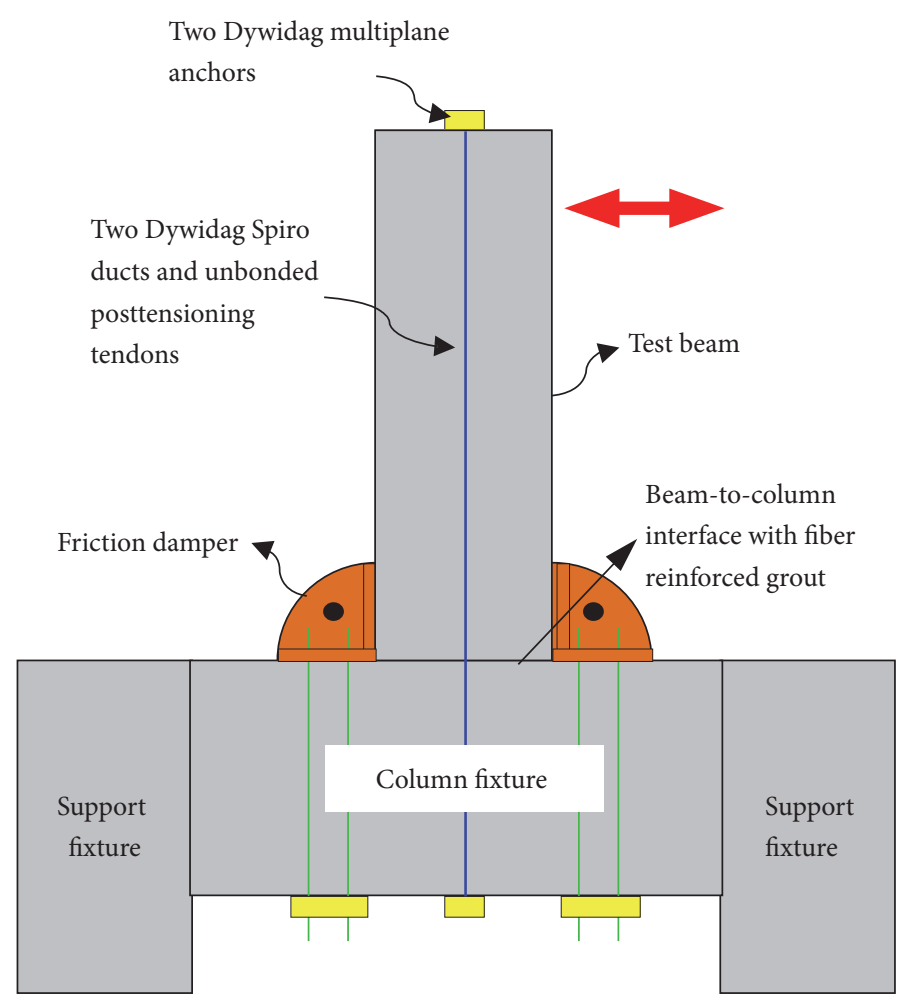

FIGURE 23: Schematic of the columns with damper (adopted from [54], copyright 2004 PCI Journal).

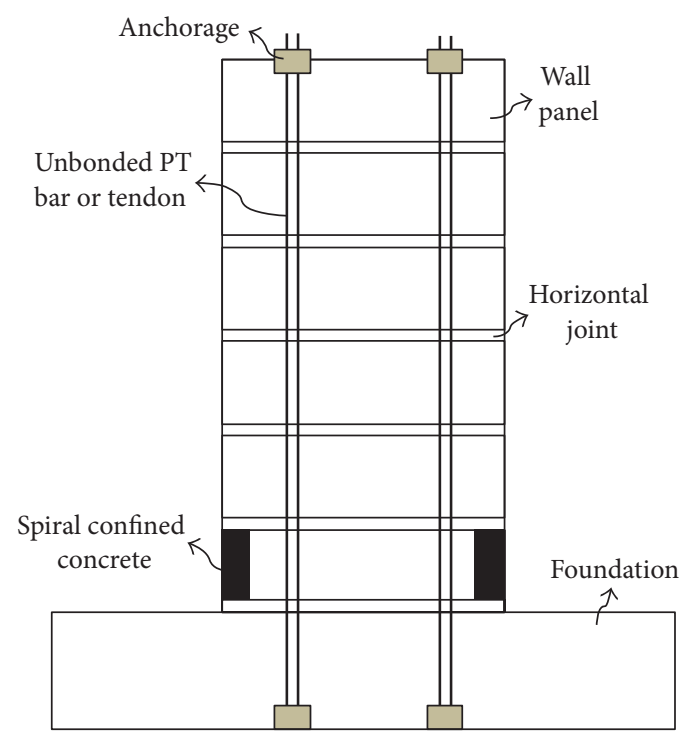

(a)

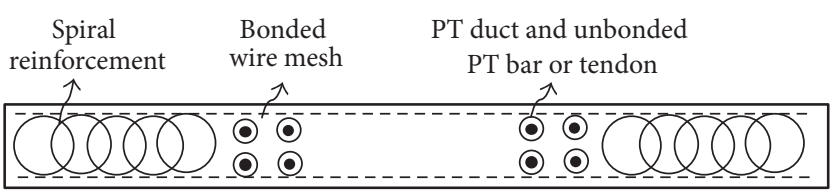

(b)

FIGURE 24: Unbonded posttensioned precast wall: (a) elevation; (b) cross section near base. (adopted from [55], copyright 1999 PCI Journal).

which consists of thin steel web plates that resist lateral loads and dissipate energy through the development of diagonal tension field action, just as in conventional SPSWs. However, the moment resisting beam-to-column connections of conventional SPSWs are replaced by posttensioned beamto-column connections to introduce the recentering capability. Winkley [146] conducted comprehensively experimental studied in detail, and Clayton et al. [147, 148] proposed design method applicable for the SC-SPSW based on the experiments.

6.4. Self-Centering Masonry Structural Wall System. Wight et al. studied seismic response of partially grouted posttensioned concrete masonry (PCM) walls with unbonded 


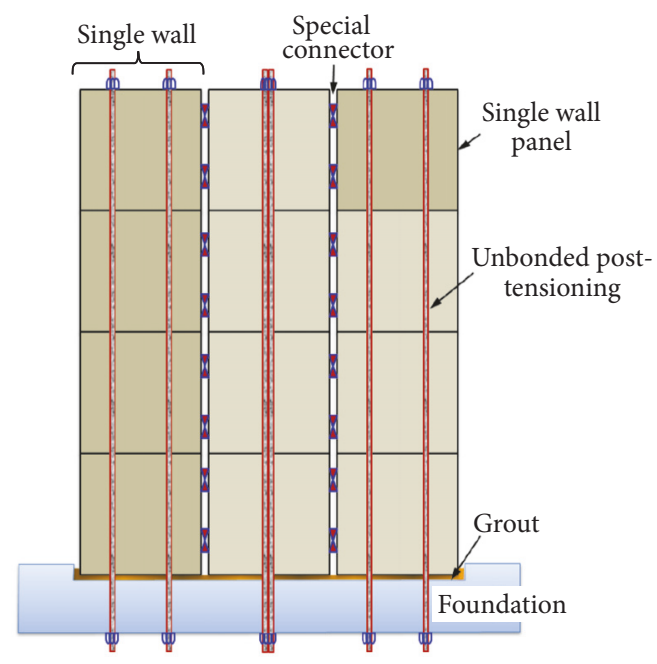

FIGURE 25: The jointed precast wall system (adopted from [56], copyright 2007 Iowa State University).

tendons by means of shake table testing. The shake table tests demonstrated the self-centering nature of posttensioned masonry walls and their ability to achieve large displacements with minimal accumulation of damage $[149,150]$.

Laursen and Ingham [151, 152] found that the energy dissipation capacity of the posttensioned fully grouted concrete masonry (PCM) wall is limited but can be enhanced by incorporating the internal energy dissipation mild steels with "dog-bone" shape $[153,154]$. The energy dissipation device has little influence on the decrease of the ductility capacity [155].

Hassanli et al. investigated the influence of axial stress ratio on seismic behaviors of unbonded posttensioned masonry wall (PT-MW) [156-160]; both experimental and numerical results showed that low axial stress ratio causes higher increase in lateral strength and better displacement ductility, but larger residual drift to PT-MW; the axial stress ratio is limited to 0.15 . The wall length is another most influential factor contributing to the rotation and the compression zone length of unbonded PT-MW. Both axial stress ratio and wall length are used to predict the flexural strength of unbonded PT-MW.

6.5. Self-Centering Timber Structural System. The NMIT Arts and Media Building is the new generation of multistory timber structures which employs an advanced damage avoidance earthquake design that is the first in the world for a timber building [62]. As shown in Figure 28, the NMIT seismic system relies on pairs of coupled LVL shear walls that incorporate high strength steel tendons posttensioned through a central duct. The walls are centrally fixed to allow them to rock during a seismic event. A series of $U$ shaped steel plates placed between the walls form a coupling mechanism and act as dissipators to absorb seismic energy. The design allows the primary structure to remain essentially undamaged while readily replaceable connections act as plastic fuses.
6.6. Self-Centering Bridge Pier Structural System. Cheng developed a self-centering bridge model that can eliminate residual deformations after earthquakes [63]. A bridge model consists of two precast RC bridge columns posttensioned to the concrete deck and foundations by high strength rods, as shown in Figure 29. The hybrid system is extended to bridge engineering, in which precast elements are connected via posttensioning techniques; self-centering and energy dissipating properties are adequately combined to achieve the target maximum displacement with negligible residual displacements; the reliability of hybrid system was confirmed by quasi-static cyclic and nonlinear time history analysis based on lumped plasticity numerical models [161].

Mohanmed et al. utilized the concrete segment which has hollow double skin cross section and situated it within the plastic hinge zone of bridge column, to mitigate the damage after earthquake; simultaneously, they used the unbonded PT strands located within the void of the inner skin to provide the self-centering force for bridge column [162-165]. The shaking table test result showed that the residual drift of the bridge column proposed by Ayman and EIGawady was smaller than the conventional RC bridge column [166]. However, the void of the hollow cross section of the proposed bridge column infilled by concrete had better seismic performance because the twist angle was smaller when it was subjected to the bidirectional cyclic loading [167].

Guo et al. $[168,169]$ developed a self-centering bridge pier system connected by unbonded posttensioned tendons to minimize the residual deformation after the earthquake and mild steel to stably dissipate the earthquake energy.

Dong et al. developed a new type of brace (SC-BRB) for bridge column system; the SC-BRB consists of the traditional buckling restrained brace (BRB) having excellent energy dissipation capacity and the self-centering brace (SC brace). The numerical results demonstrated that the bridge equipped with the SC-BRB system has smaller residual displacement and a moderate energy dissipation capability compared to the ones equipped with traditional BRB and SCB systems [170].

\section{Analysis and Design Seismic Behavior of DRSRS System}

The high performance damage-resistant seismic resisting structural (DRSRS) system is capable of eliminating the most or full residual deformation when the lateral load is removed. In general, the DRSRS system consists of posttensioned bar (PT) and energy dissipation element (EDE) such that the dominant structural element can be protected through the gap opening mechanism, and the PT is used to eliminate the residual deformation due to the self-centering capacity of it, the EDE is used to dissipate the earthquake energy.

The PTs contain high strength strands, tendons, or bars $[57,68,171]$, and the PTs should have high strength and high yield strain. The EDEs consist of hysteretic damping elements, viscous damping elements, and frictional damping elements. Hysteretic damping elements used in self-centering systems include buckling restrain braces [172-174], short yielding elements similar to the buckling restrain braces $[175,176]$, 


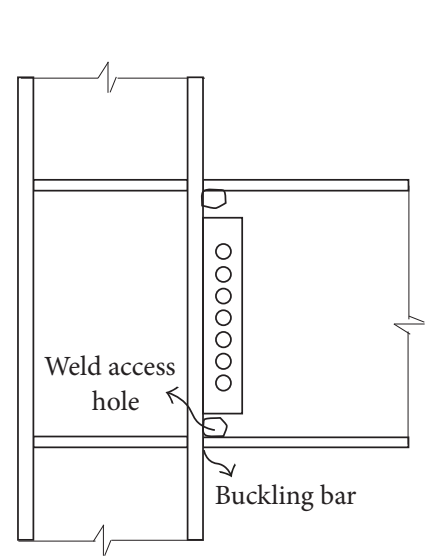

(a)

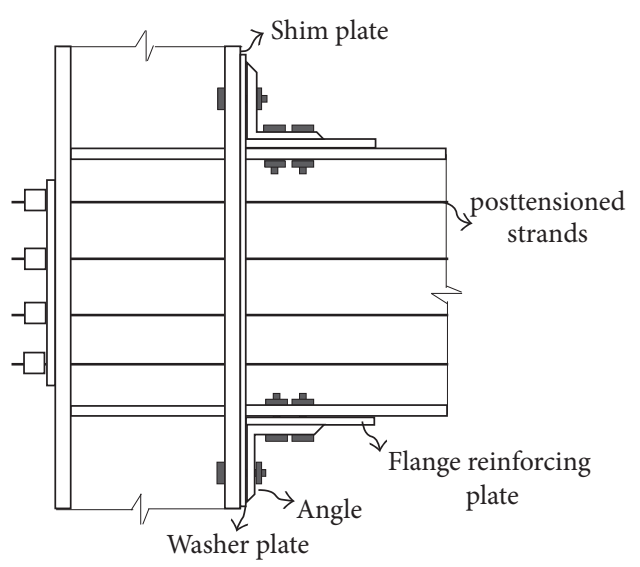

(b)

Figure 26: Moment connections: (a) pre-Northridge welded connection; (b) posttensioned connection (adopted from [57], copyright 2001 Journal of Structural Engineering, ASCE).

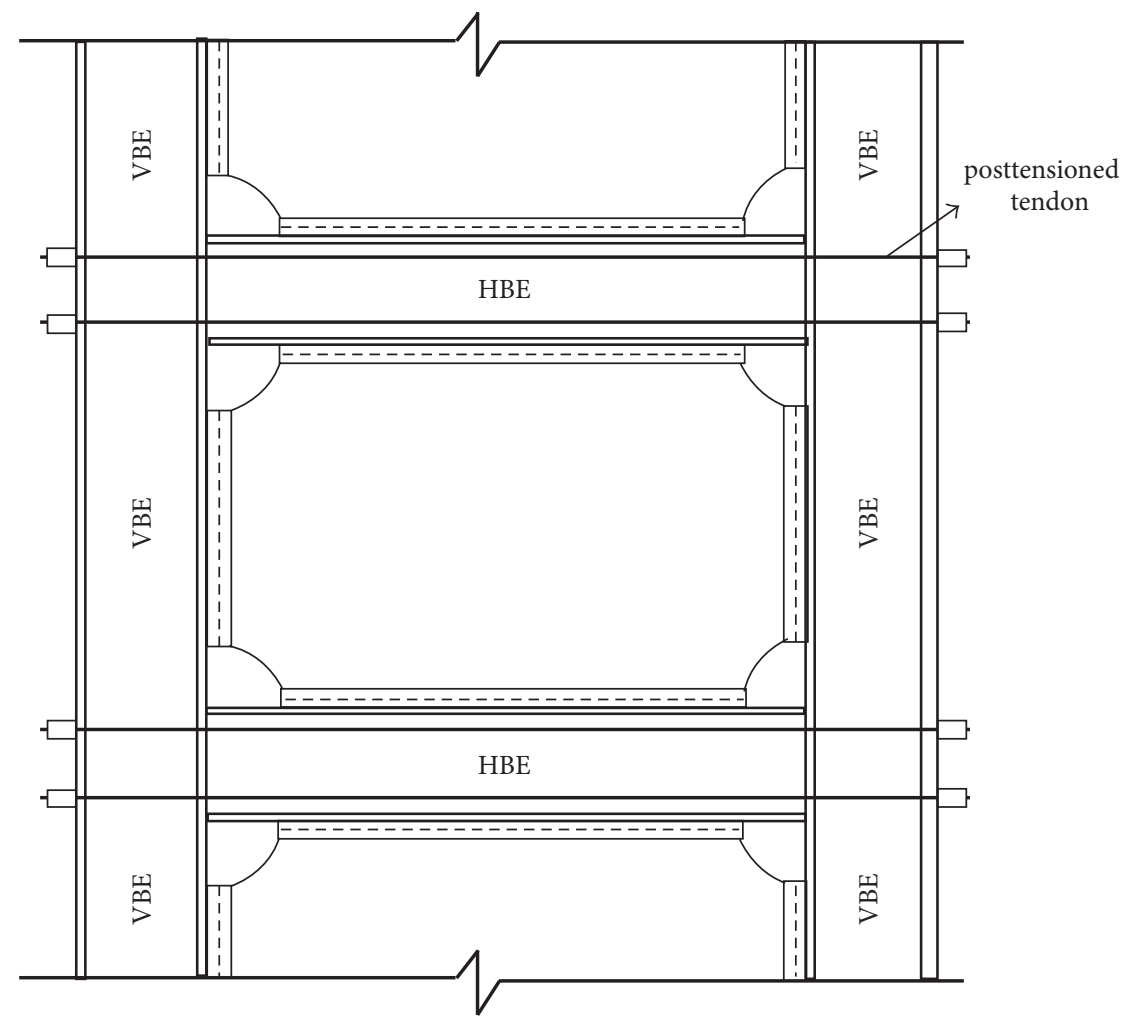

HBE: horizontal boundary elements

VBE: vertical boundary elements

FIGURE 27: Schematic elevation of intermediate story of SC-SPSW (adopted from [61], copyright 2010 University of Washington).

unbonded mild steel reinforcement $[177,178]$, steel reinforcement with reduced sections [129], yielding anchor bolts [179], fuse plates [180], yielding end plates [181, 182], yielding angles $[69,183]$, web hourglass pins [184], and tapered steel cantilever plates [111]. The frictional damping elements used contain frictional slide plate [185], frictional plates with spring washers [186], frictional fuse angle with slotted holes
[187], and viscous fluid damper [188] embedded in the foundation or mounted beside the columns above the foundation.

The hysteretic behavior of structural systems with PT and EDE is as shown in Figure 30; the PT has strong recentering force to pull the whole structural element back, shown in Figure 30(a); however, it has little energy dissipation capacity. The EDEs have great energy dissipation capacity, 


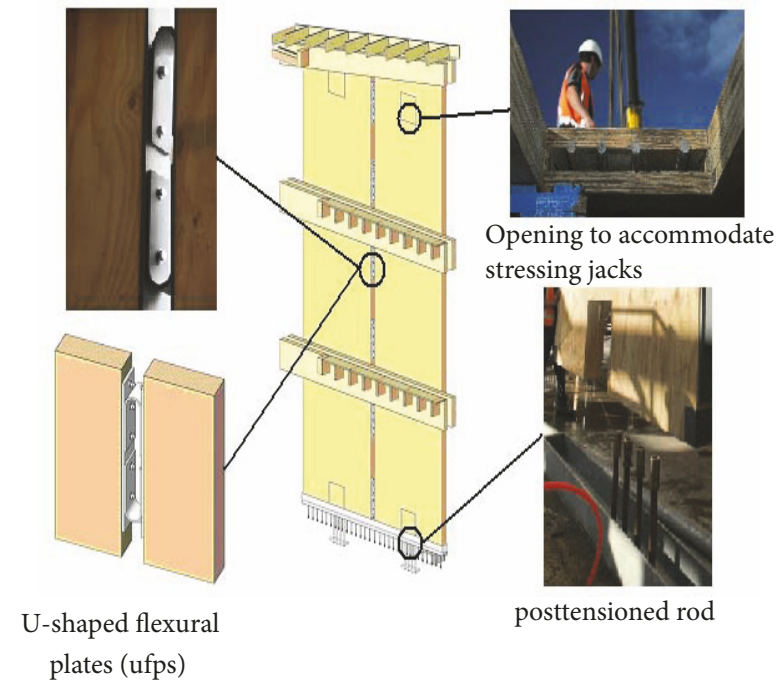

FIGURE 28: LVL coupled shear walls showing posttensioning rods and U-shape flexural plates (UFPs) energy dissipating devices (adopted from [62], copyright 2011, 9th Pacific Conference on Earthquake Engineering).

shown as in Figure 30(b); consequently, they are incorporated into the DRSRS system to enhance the energy dissipation capacity, as shown in Figure 30(c). The overall response of the DRSRS system can be decomposed into the nonlinear elastic contribution from the prestressed tendon or strand (PT) and the bilinear elastoplastic hysteretic contribution from the energy dissipation element (EDE).

7.1. Analysis of Monotonic Seismic Behavior and Design of DRSRS System. To estimate the seismic behavior of DRSRS system in numerical method, some works have been performed. Wight [189] developed a finite element model to assess the monotonic response of posttensioned masonry wall; a reasonable seismic strength and postrocking behavior could be simulated; however, the initial stiffness was overestimated and the strength degradation could not be predicted. Smith et al. [127, 128] attempted to use two different analytical models to evaluate the seismic behaviors of the test structure: a fiber-element model (DRAIN-2DX) and a finite element model (ABAQUS); in the models the fiber beam-column elements are to represent the precast wall panels and truss elements for the unbonded PT steel.

A finite element model was proposed by Ryu et al. [190] to analyze the reversed cyclic seismic response of unbonded posttensioned (PT) fully grouted clay brick walls, and a good comparison between the experimental results and the numerical results was presented. The ABAQUS software was used by Henry et al. [191] to the cyclic lateral load response of the PreWEC which consists of a precast wall with end columns. The precast wall and the end columns are connected by some O-shape connectors. The model could predict good results of the PreWEC system for both the global and local responses.

The multispring element to model the opening and closing of the gap at the critical interface section is used to predict the seismic behavior of the hybrid pier systems $[161,192]$. Li et al. [193] utilized the ABAQUS numerically to study the seismic performance of precast segmental concrete columns reinforced by the posttensioned tendon at the center of the cross section; the opening and closing between the concrete segments are simulated by using the surface to surface contact elements. This finite element method could rationally estimate the self-centering behaviors of test columns subjected to the cyclic loading.

Although the finite element method can effectively evaluate the seismic response, it involves computational difficulties that make it unsuitable for the designer. Kurama et al. [55] assumed that the responses of posttensioned concrete wall can be characterized by some limit states, graphically shown in Figure 31. As the wall displacement increases, the limit states are summarized: (1) decompression state, which identifies the initiation of a gap opening along the horizontal joint between wall and foundation; (2) softening state, which identifies the beginning of significant reduction in the lateral stiffness of the wall due to the gap opening along the horizontal joint and the nonlinear behavior of the concrete in compression; (3) yielding state, which identifies the point at which the posttensioned steel yields; (4) failure state, which identifies the axial-flexure of the wall which occurs as a result of crushing of the confined concrete. Furthermore, the design approach, design objectives shown in Figure 31, design criteria, and seismic design procedure were proposed in detail by Kurama et al. [55].

Perez et al. [126] proposed a trilinear model to predict the nonlinear lateral response of unbonded PT-CWs based on the above-mentioned limit states shown as in Figure 31. Aaleti and Sritharan [139] developed a simplified approach using a trilinear function of the neutral axis depth at a drift of $2 \%$. Hassanli et al. [194] developed an analysis procedure to characterize the lateral force behavior of unbonded posttensioned concrete walls (PT-CWs) based on the mechanics of rocking walls and geometric compatibility conditions; the force-displacement curve of unbonded PT-CW could be predicted with a very good accuracy.

Madan et al. [195] proposed an analytical approach for predicting the nonlinear in-plane flexural behavior of longitudinally posttensioned hollow block masonry shear walls under reversed cyclic lateral loading based on a modified fiber-element model. Kalliontzis and Schultz [196] developed a simplified procedure based on the equivalent stress block analysis and the neutral axis depth (NAD) versus wall rotation relationship proposed by Thomas and Sritharan [197]; the comparison with the finite element method showed that the above-proposed analysis method could adequately capture the experimental force-displacement responses. Furthermore, the in-plane flexural strength of unbonded PT-CW for the designer can be evaluated using the equation proposed by Hassanli et al. [160].

For the self-centering posttensioned steel frame (SCPTSF) systems, the desired limit state progressions of the SCPTSF system using PT bars and PT strands are schematically shown in Figures 32(a) and 32(b). Similar to the self-centering concrete wall system, the limit states of SCPTSF system are summarized as follows $[64,65]$ : (1) decompression and uplift of the 


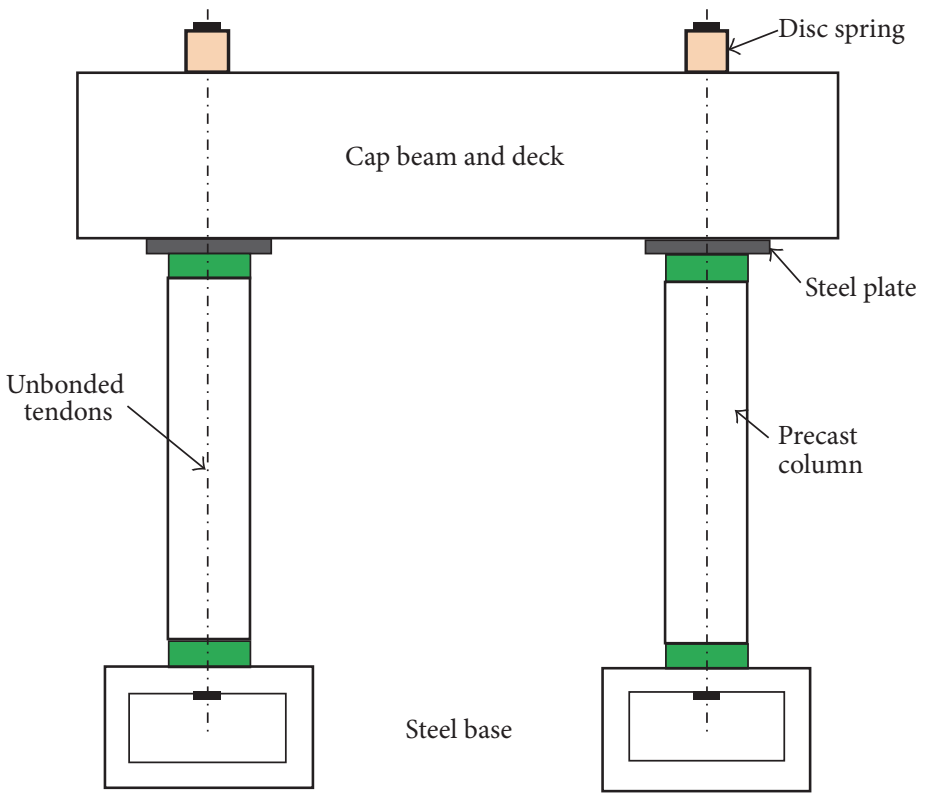

FIGURE 29: A self-centering designed bridge model (adopted from [63], copyright 2008 Engineering Structures).

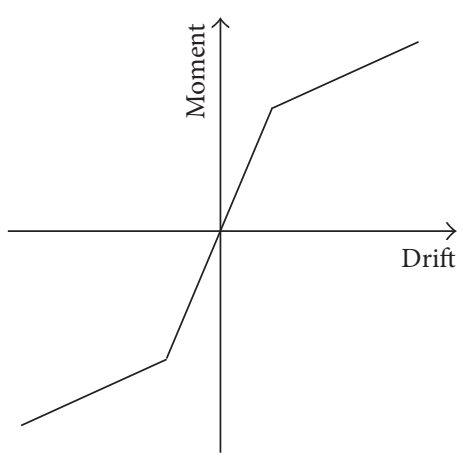

(a)

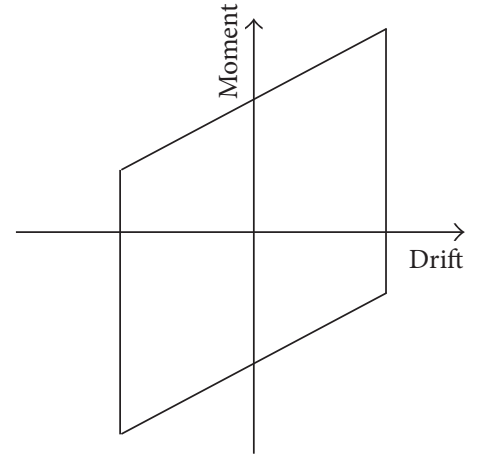

(b)

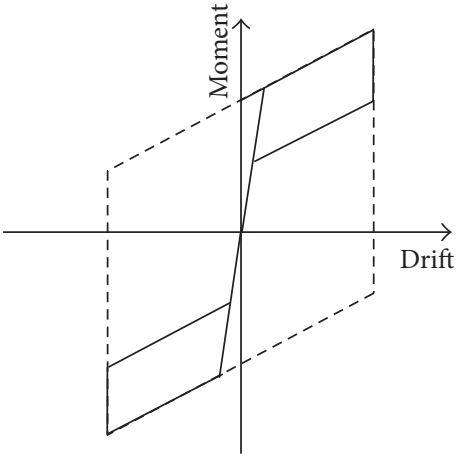

(c)

FIGURE 30: Idealized hysteretic behavior of the DRSRS SYSTEM: (a) contribution of prestressed tendon (PT); (b) contribution of energy dissipation element (EDE); (c) moment-drift relationship of DRSRS SYSTEM.

"tension" column at the base; (2) yielding of the PT steel: this limit state progression depends on the type of PT steel used and the type of self-centering system; the rocking steel braced frames with PT bars; this limit state is due to the yielding of PT bar, shown in Figure 32(a); for the moment resisting frame with PT strands, the limit state is caused by system, shown in Figure 32(b); (3) significant yielding of the beams, columns, or braces of self-centering braced frame; (4) failure of the beams, columns, or braces of the self-centering braced frame or PT strand yields. Similar research works were done by Garlock et al. for SCPTSFS [65], as shown in Figures 32(a) and 32(b).

7.2. Residual Deformation of DRSRS System. The DRSRS system is developed to eliminate the residual deformation, and its self-centering capacity is characterized by the resistances due to the restoring force from PT and the force in the energy dissipation element. Two independent response parameters $\alpha$ and $\beta$ were considered to control the self-centering capacity of DRSRS system, shown as in Figure 33; the coefficients $\alpha$ and $\beta$ reflect the postyielding stiffness and the energy dissipation capacity of the DRSRS system, respectively. The influence of the variation of the parameters $\alpha$ and $\beta$ on the hysteretic behavior and ductility of DRSRS SYSTEM was discussed in detail, the displacement ductility was reduced in all cases for increasing values of $\alpha$ and $\beta$ [78]; the residual drift decreases with increasing the postyielding stiffness $\alpha$ and decreasing the coefficient $\beta$ [198].

Christopoulos et al. $[199,200]$ estimated the residual deformations of the SDOF and MDOF systems which are representative of frame structures, the analysis results showed that the residual deformations are significantly sensitive to the hysteretic rules, the postyielding stiffness, the expected global inelastic mechanisms, and the seismic intensity.

Although the response of self-centering system can be characterized as an idealized flag-shape behavior, it is no 


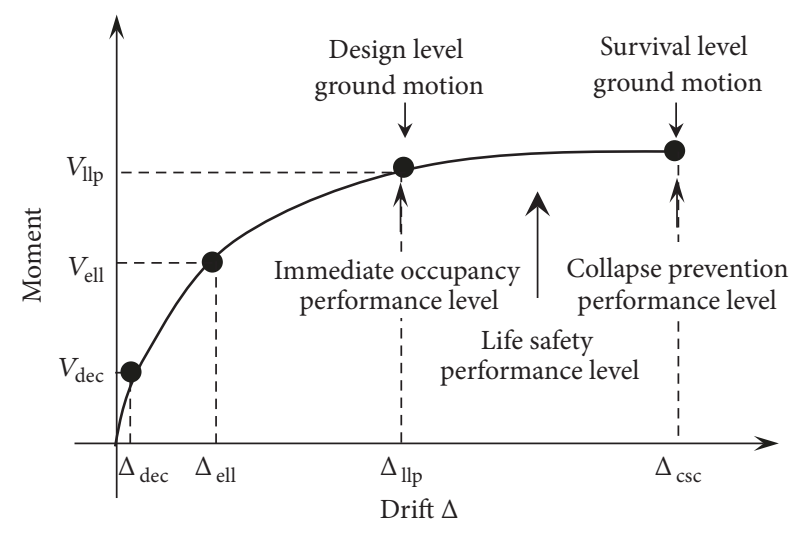

FIGURE 31: Base shear-roof drift relationship and design objectives of SCPTPSWS (adopted from [55], copyright 1999 PCI Journal).

possible to exist for the real entire structure system due to (1) the interaction with other structural and/or nonstructural elements in a building $[198,201]$ and (2) the fact that the responses of the PT member and energy dissipating components cannot be simply added together because energy dissipating elements are only engaged after decompression followed by uplift at the tension zone [202].

The realistic hysteresis response of a self-centering structural system needs to consider the effects of dynamic selfcentering capacity. Christopoulos et al. found that the residual drift at the end of dynamic response is typically less than the maximum residual drift of the cyclic hysteretic loop due to the postpeak behavior called the "shake-down" phenomenon, respectively [199, 203]. Henry et al. [202] found that the residual drift ratio, which is defined as the ratio of the residual drift at the end of the dynamic analysis to the maximum static or cyclic residual drift, has no significant correlation with the fundamental period, hysteretic energy dissipation, the ground motion parameters, and the viscous damping of structural system by investigating the dynamic self-centering behavior of the PreWEC concrete wall system. Henry et al. further established the residual drift limit for the real self-centering PreWEC concrete wall system, which is limited to $0.2 \%$ for a design level earthquake and $0.3 \%$ for a maximum considered earthquake, based on the recommendations by Rahman and Sritharan [136, 178].

For designing the expected self-centering PT concrete member, ACI design guidelines [204] limited the moment contribution from energy dissipating (ED) reinforcement so that it must be less than $50 \%$ of the probable flexural moment of the member, and the value proposed in New Zealand [205] is 46\%. ITG-5 [206] indicated that the self-centering capacity may be significant loss if the ED device contributes more than $40 \%$ of the flexural capacity. Henry et al. [202] found that the PT and ED moment contributions are only critical when the structure is unloaded to zero, meaning that the above-proposed value may result in conservative and unconservative estimation of the self-centering ability of structure.

\section{Current Research Challenges in High Performance DRSRS Systems}

8.1. Floor Diaphragm Connections in DRSRS Systems. In conventional moment resisting frame, the seismic inertial forces are transferred from the floor diaphragm to each beam; however, this mechanism is problematic for the self-centering moment resisting frame, because gap opening at the connections causes a PT frame to "expand" after decompression, as shown in Figure 34 [65]. In the deformed position, the distance between the column centerlines is larger than in the original undeformed position due to connection gap opening, and the PT frame expansion increases with the number of bays, shown in Figure 34(b).

To resolve this problem, many approaches were studied. One detailed approach was proposed in which the floor diaphragm in the moment resisting frame per floor is attached to one beam, and the floor diaphragm and beams in all other bays are noncomposite, which permits the beam to move relatively to the floor diaphragm [65]. It is proposed that the beam-column connection can rock at the beam bottom flange while the beam top flange with the column is preserved all the time [207]. A sliding slab is used to minimize restraints on the expansion of the PT frame, in which a composite slab is rigidly connected to the beams in a single bay of the PT frame, and a sliding device is installed between the floor beams and the beams in other bays such that the slab is allowed to slide $[208,209]$.

Henry et al. [191, 210] proposed an isolated floor connection to minimize the damage of the floor due to the rocking wall, in which the floor is connected to the end column of the rocking wall system, and the end column is connected with the wall using some O-shape connectors.

8.2. Higher Mode Effects. Some studies [211, 212] have demonstrated that the higher modes contribute significantly to the force demands of controlled rocking frame members, so rocking does not fully limit the peak seismic forces because of higher mode effects. To limit higher mode effects in controlled rocking steel frames, Wiebe et al. [105, 213-215] proposed two types of higher mode mitigation mechanisms: the first mitigation mechanism is formed by allowing the upper section of the frame to rock, so as to better control the midheight overturning moment; the second mitigation mechanism is formed by replacing the conventional first-story brace with a self-centering energy dissipative (SCED) brace, so as to better control the base shear. Experimental and numerical results suggested that the proposed mechanisms can enable better capacity design by reducing the variability of peak seismic force demands without causing excessive displacements. Although this approach could reduce the effect, further research is needed on this topic.

8.3. Collapse Safety Assessment. The DRSRS system is developed to reduce or eliminate residual deformation under design seismic level; however, it is still possible to undergo the very rare and intense earthquakes which are not included in the predicted design seismic level, meaning that the DRSRS system may collapse. So far studies on this topic are very 


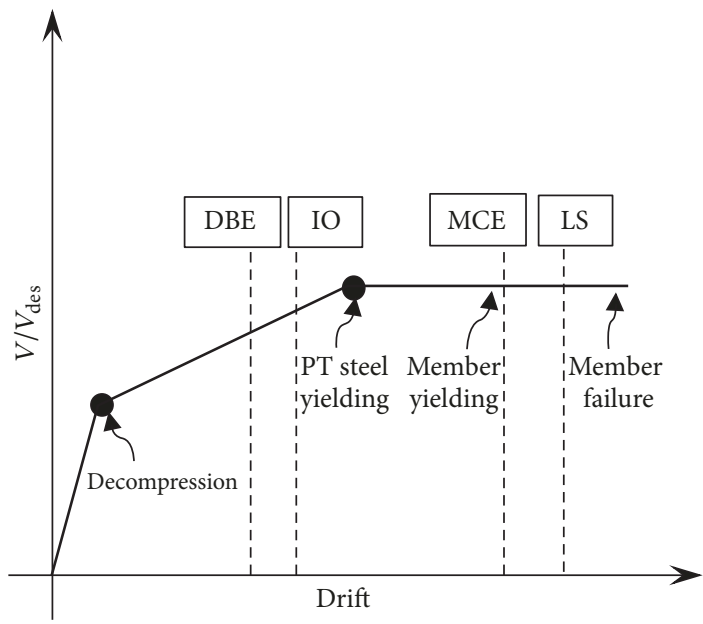

DBE: designed basis earthquake IO: immediate occupancy MCE: maximum considered earthquake LS: life safety

(a)

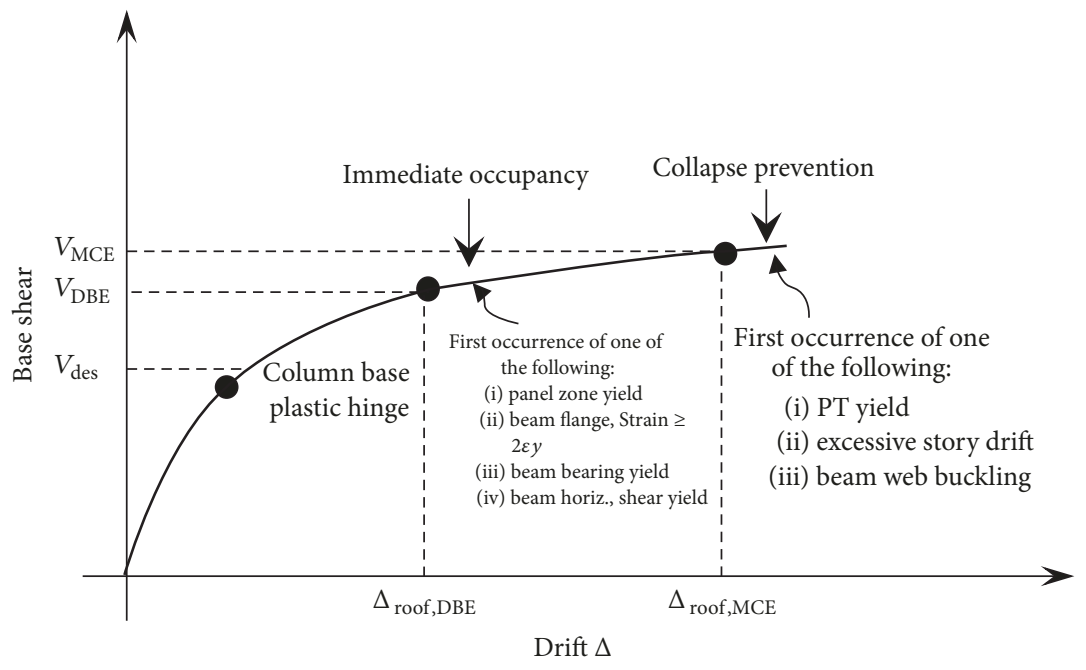

(b)

FIGURE 32: Base shear-roof drift relationship and design objectives of SCPTPSWS: (a) rocking braced frame with PT bars (adopted from [64], copyright 2006, 5th International Conference on Behavior of Steel Structures in Seismic Areas); (b) moment resisting frame with PT strands (adopted from [65, 66], copyright 2007, 14WCEE, ASCE).

limited [216, 217] and the research on this topic should be ongoing.

8.4. Life Cyclic Cost Assessment. In general, the structural system of self-centering structures is different from conventional structural system, which leads to additional complexity in design, fabrication, and erection of the self-centering system. For example, the anchorage construction of prestress tendon in the foundation is difficult, which may increase construction costs; as a result, even the savings due to the damagefree performance will offset the increased initial cost over the life of the structural system. Thus, life-cycle cost analysis must consider not only the structural repair costs but all elements of the structure. Studies on quantifying the life-cycle costs of DRSRS system are ongoing [218-221] and need to be further researched in future.

8.5. Building Code Provision for Design. The purpose of the DRSRS system differs from the conventional structure, so the design methodology and the detailing requirement of DRSRS system will be very different from the conventional structure. Despite the attempts to propose design approaches for the precast posttensioned wall system and the posttensioned steel frame system $[55,65]$, the entire design system which should 


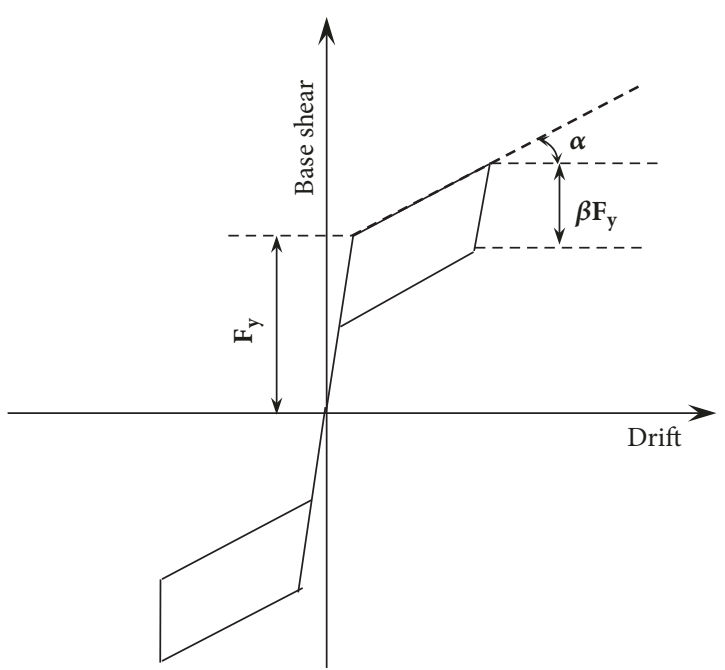

FIGURE 33: Idealized pseudo-force-drift relationship of DRSRS SYSTEM (adopted from [78], copyright 2002 John Wiley \& Sons, Ltd).

be included in building code provision to guide the design of DRSRS system in the actual construction has not been established yet.

8.6. Assessment of Influence of Prestress Lost on the Structural System. So far the most popular DRSRS system mainly uses the prestress tendon or strands (PT) to provide the selfcentering capacity. As is well known, the prestress methodology has inherent shortcoming "prestress loss." Consequently, for the DRSRS system using the PT, how to evaluate the loss in the stress of the PT at large lateral deformation and the influence of the loss on seismic performances of structures is the unavoidable problem for using the PT bar, especially the prestress loss that lasts within the long serviceable period of DRSRS system.

\section{Current New Research Highlights in High Performance DRSRS Systems}

In order to reduce the additional constructed cost due to the difficulties in the detailing requirement such as the anchorage of PT and the designation and to avoid the shortcoming of prestress methodology used in the DRSRS system, recently, another method to develop resilient concrete structures by using the inherent elastic resilient capacity of tensile longitudinal bar was proposed, which should be paid more attention.

In order to obtain enough ductility, Pandey et al. [222225] experimentally and numerically found that decreasing properties of bond strength of longitudinal bars could greatly improve the ductility of concrete. Tanaka et al. [226] thus used the unbonded high strength steel bar as the tensile longitudinal bar to reinforce the concrete columns; the experimental result showed that the columns exhibited strong self-centering hysteresis response performance; however, the lateral resistance capacity is smaller than that calculated by the current design codes.
To overcome the problems in the method of using PT or unbonded rebars, Sun et al. [227-229] have recently proposed using a special ultrahigh strength rebar (SBPDN 1275/1420 rebar) with low bond strength as longitudinal rebar in concrete members. The SBPDN rebar has a spiral groove on its surface and has a low bond strength of about 1/5 of deformed rebar [79]; the difference between the SBPDN bar and conventional high strength steel bar USD 685 is shown as in Figure 35. The structural detailing of column proposed by Sun et al. is shown in Figure 36; the reinforcement playout of the proposed column is the same as that of the conventional column; however, due to the poor flexibility of SBPDN rebar, all the SBPDN bars are anchored by steel tie plates which are connected by nuts and bolts at both ends and middle contraflexure section of column. In addition, due to the ultrahigh strength of SBPDN rebar, the column section is confined by two semisteel plates which are connected by nuts and bolts to enhance the shear-resisting capacity such that the shear failure can be avoided.

In recent years, they performed extensive experimental study on the seismic behaviors of rectangular or circular columns reinforced by SBPDN bars; the results demonstrated that concrete columns using SBPDN rebar and steel plates exhibited stable cyclic behavior up to large deformation and very small residual deformation compared to the columns using conventional high strength steel rebar (USD685) [230234].

Wang et al. proposed sustainable and resilient concrete columns with a large quantity of fly ash (LQFA) reinforced by SBPDN bars in order to use largely fly ash into concrete construction $[19,80]$. The experimental results of resilient LQFA concrete columns showed that columns using SBPDN rebar having low bond strength as the longitudinal bar had excellent drift angle up to $0.04 \mathrm{rad} \sim 0.05 \mathrm{rad}$ and small residual deformation.

To assess the seismic responses of concrete columns reinforced by SBPDN bars having low bond strength, Funato et al. [79] have proposed an integrated analytical method that could evaluate reasonably cyclic behaviors of concrete columns by considering the slippage of longitudinal bars. This method, however, involves tedious double-loop iteration procedures to find the balanced depth of neutral axis in the targeted column section and to obtain the slippage of longitudinal rebars from their anchorage zones. Consequently, Wang [235] proposed a simple analytical procedure to calculate the structural performances of concrete member reinforced by steel having different bond strength and an equation to calculate the deformation at the maximum lateral load. The comparison results indicated that the proposed analytical method and equation could reasonably assess the seismic responses of concrete column reinforced by steel with different bond strength level.

\section{Conclusions}

Beacuse the majority of the population in the world lives concentrically in cities, basically, it is consensus to develop high performance seismic resisting structural (DRSRS) system for the sustainable and resilient city. The high cost of repairing 


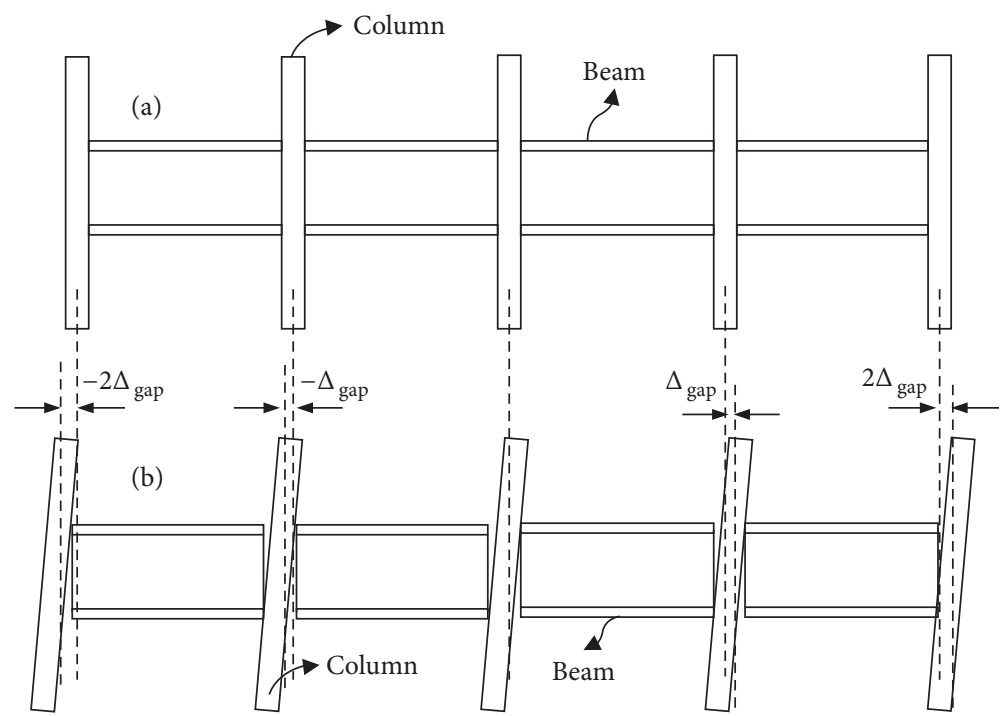

FIGURE 34: Elevation of one floor of a DRSRS SYSTEM: (a) undeformed; (b) deformed configurations (adopted from [65], copyright 2007 Journal of Structural Engineering, ASCE).

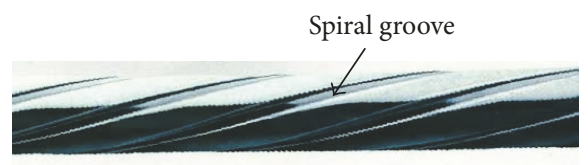

(a) SBPDN 1275/1420 rebar

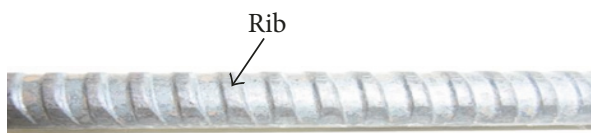

(b) USD 685 rebar

FIGURE 35: The difference between conventional steel and SBPDN steel (adopted from [79], copyright 2012 JCI).

the damaged engineering structures after earthquake compels engineers and researchers to develop the innovative structural system which can eliminate the residual deformation. Based on the principles of "replaceable" and weakening the connections between structural elements such as upper structures and foundation, beam-column intersection, three types of DRSRS systems are developed and ongoingly studied: (1) replaceable structural element (RSE); (2) rocking seismic resisting structural (RSRS) system; (3) self-centering seismic resisting structural (SCSRS) system.

This paper summarized the research status and achievements of the existing DRSRS systems; the main conclusions are illustrated as follows:

(1) The test results indicated that the shear wall system with replaceable coupling beam has smaller postearthquake damage compared to the conventional shear wall system. The energy dissipation devices can be utilized as either an independently replaceable coupling fuse section or jointly used with replaceable coupling beam together into the shear wall system.

(2) Rocking seismic resisting structural (RSRS) systems have been extended into bridge engineering structure, RC frame system, steel frame system, RC shear wall system, masonry wall and timber structural system, and core wall system. The extensive experimental study results showed that RSRS systems with types of energy dissipation devices can greatly limit the damage and the residual deformation of the structural system after loading and can possess good energy dissipation capacity.

(3) The posttensioned prestress tendon and strand are used to provide the self-centering capacity for the structural system. The dissipation devices are included to enhance energy dissipation capacity of the selfcentering seismic structural (SCSS) systems. Extensive experimental programs indicated that the combination of posttensioned tendon and energy dissipation devices could minimize the damage and the residual deformation after loading and behave with good energy dissipation capacity.

(4) Types of numerical models including the finite element method can reasonably analyze the cyclic and dynamical responses of RSRS and SCSS systems. Some equations have been proposed to design the self-centering shear wall system.

(5) The residual deformation at the end dynamic response is smaller compared to the static cyclic loading; despite the attempts to propose design limit of residual deformation for the precast concrete shear wall system, the analyses of the residual deformation 


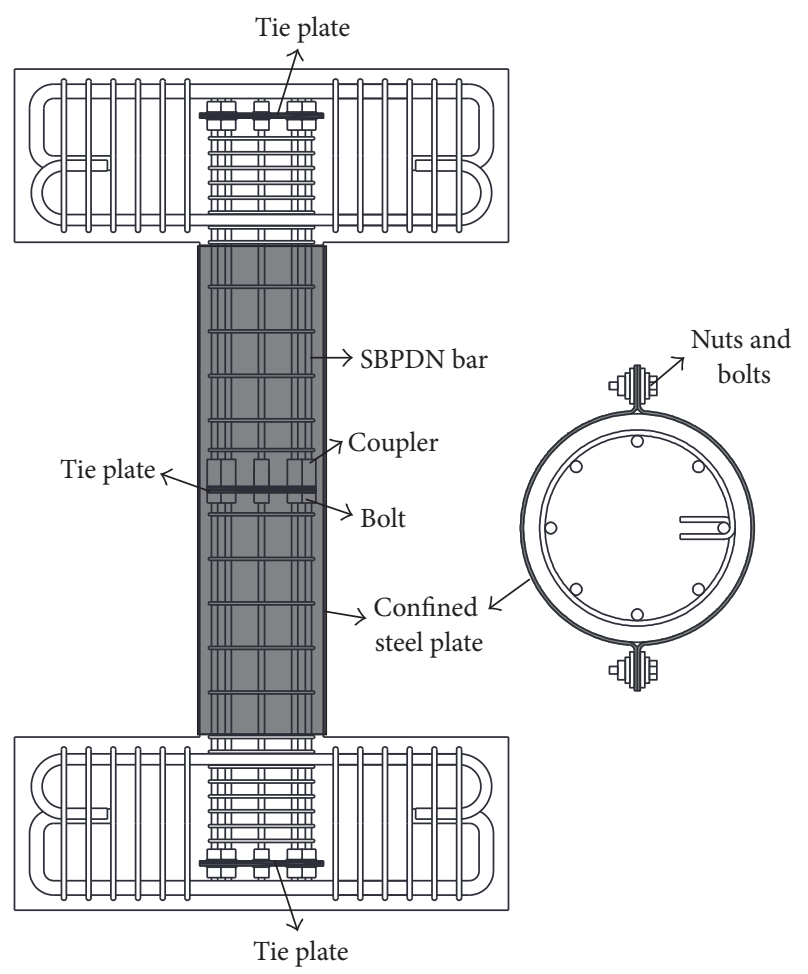

(a)

(b)

Figure 36: The playout of specimen with SBPDN steel bar: (a) elevation of column; (b) cross section (adopted from [80], copyright 2015 JCI).

for other resilient structural forms and for the entire structural system are limited.

(6) Ongoing challenges for SCSRSS include (1) addressing the floor diaphragm connections to beam and column, (2) mitigating the adverse effect of higher mode effects, (3) collapse safety assessment, (4) life cyclic cost assessment, (5) building code provision for design, and (6) assessment of influence of prestress loss on seismic responses of the structural system.

(7) The new research viewpoint using high strength steel bar with the low bond strength to develop the resilient structural system which showed stable cyclic behavior up to large deformation and good self-centering capacity should be paid more attention and enthusiasm due to its simple structural technology.

\section{Recommendations for Future Studies}

(1) The principle of the replaceable structural element (RSE) should be extensively used to the other structural system, for example, the plastic hinge zones of the column and beam and the foot toes of the wall systems where concrete is crushed due to the compression in usual. Furthermore, the analysis and design approach of RSE should be further studied.

(2) The analysis and experiments on the response of the entire structural system with self-centering member and other nonstructural elements which may decrease the self-centering capacity should be further performed.

(3) The dynamic analysis to determine the residual deformation of the DRSRS system or structural system using other materials such as high strength FRP rebar and SBPDN rebar should be conducted. The design equation of the residual deformation under reversed cyclic seismic loading should be proposed.

(4) It is not advocated to use complicated and high cost engineering technology to develop DRSRS systems; on the contrary, simple and low-cost technology is encouraged when considering the future popularization specially in the poverty area or country.

(5) The potential imperfections of DRSRS system such as higher mode effect, the connection of floor and the self-centering member, prestress loss, and degradation in the initial stiffness should be deeply studied and eliminated.

(6) Due to the simple structural technology and detailing, using high strength steel with poor bond strength property to develop the self-centering structural system is an alternative that should be paid more attention and deeply studied.

\section{Additional Points}

Highlights. (i) The current research status and achievement of existing DRSRS systems such as replaceable structural element, rocking structural system, and self-centering structural system for sustainable and resilient city are summarized in detail. (ii) The current research highlights that emerged using high strength steel bar with poor bond strength property to develop DRSRS system are illustrated. (iii) The current research challenges of DRSRS system and the recommendations for the future studies are pointed out and discussed.

\section{Conflicts of Interest}

The authors declare that they have no conflicts of interest.

\section{Acknowledgments}

The research reported in this paper was supported by the National Natural Science Foundation of China (Project no. 51708288), the National Natural Science Foundation of China (Project no. 41772317), and the Opening Fund of State Key Laboratory of Geohazard Prevention and Geoenvironment Protection of Chengdu University of Technology (Project no. SKLGP2016K005). The authors also would like to express their gratitude and sincere appreciation to the Department of Architecture, Graduate School of Engineering, Kobe University, and College of Civil Engineering at Nanjing Tech University. 


\section{References}

[1] United Nations, "epartment of Economic and Social Affairs (UNDESA), Population Division, World Population Prospects: The 2015 Revision, Key Findings and Advance Tables," 2015, https://esa.un.org/unpd/wpp/.

[2] ICLEI, "ICLEI Seoul Strategic Plan 2015-2021: Building a World of Local Actions for a Sustainable Urban Future," 2015, http:// www.iclei.org/fileadmin/user_upload/ICLEI_WS/Documents/ Publications/Strategic_Plan_low-res_rev.pdf.

[3] X. Wang, X. Ding, L. Wang, and Y. Wang, "A study on fast earthquake loss assessment and its application to 2008 Wenchuan M8 earthquake," Earthquake Science, vol. 31, no. 2, pp. 205-211, 2009.

[4] K. Norio, "The Great Hanshin Awaji Earthquake, Housing," Livelihood ., Kobe, K TEC, 2013.

[5] Y. Honjo, Summary of damages from and reconstruction measures for, Great East Japan Earthquake., Kobe, Kobe Institute of Urban Research, 2013.

[6] Resilient Cities Report, "Global developments in urban adaptation and resilience," in The 7th Global Forum on Urban Resilience and Adaptation, Bonn, Germany, July 2016.

[7] R. E. Swiss, Preliminary sigma estimates for first-half 2016: natural catastrophes drive global insured losses to USD 31 billion, Preliminary sigma estimates for first half 2016 natural catastrophes drive global insured losses to USD, 2016, http://www .swissre.com $/ \mathrm{media} /$ newsreleases.

[8] R. E. Swiss, 2016, Earthquake Italy, August 2016: First Facts For You At A Glance, http://www.swissre.com/library/factsheetspublication/earthquake.

[9] Report of the seventh joint planning meeting of NEES/E-defense collaborative research on earthquake engineering, Berkeley, University of California, Berkeley, PEER, 2010.

[10] FEMA 273, NEHRP guidelines and commentary for seismic rehabilitation of buildings. Wash, DC, USA, Federal Emergency Management Agency, 1997.

[11] FEMA 356, Prestandard and commentary for the seismic rehabilitation of buildings. Wash, DC, USA, Federal Emergency Management Agency, 2000.

[12] FEMA 445, Next-generation performance-based seismic design guidelines: program plan for new and existing buildings. Wash, DC, USA, Federal Emergency Management Agency, 2007.

[13] T. Zhang, T. Bo, and JY. Lai, "Comparative study of earthquake recovery and reconstruction between China and Japan," Journal of Natural Disasters, vol. 23, no. 4, p. 12, 2004.

[14] R. P. Jiang, "The influence of the Great Japan Earthquake on Japanese economics," in Japanese Studies, 2011.

[15] New Zealand Treasury, Budget Policy Statement, New Zealand Government, 2013.

[16] S. H. Potter, J. S. Becker, D. M. Johnston, and K. P. Rossiter, "An overview of the impacts of the 2010-2011 Canterbury earthquakes," International Journal of Disaster Risk Reduction, vol. 14, pp. 6-14, 2015.

[17] S. Ohtani, "Development of performance-based design methodology in Japan," in Proceedings of International Conference at Bled, pp. 59-68, 1997.

[18] K. Kawashima, "Japanese seismic design specifications of highway bridges and the performance-based design," in Proceedings of International Conference at Bled, pp. 229-240, 1996.

[19] J. H. Wang, T. Takeuchi, T. Koyama, and Y. P. Sun, "Seismic Behavior of Circular Fly Ash Concrete Columns Reinforced by
Ultra High Strength Rebar and Steel Plates," in Proceedings of the Japan Concrete Institute, vol. 36, pp. 115-120, 2014.

[20] M.-C. Tang and R. Manzanarez, "San Francisco-Oakland Bay Bridge design concepts and alternatives," in Proceedings of the 2001 Structures Congress and Exposition, Structures 2001, USA, May 2001.

[21] P. J. Fortney, B. M. Shahrooz, and G. A. Rassati, "The next generation of coupling beams," in Proceedings of the 5th International Conference on Composite Construction in Steel and Concrete V, pp. 619-630, zaf, July 2004.

[22] P. J. Fortney, B. M. Shahrooz, and G. A. Rassati, "Large-scale testing of a replaceable "fuse" steel coupling beam," Journal of Structural Engineering, vol. 133, no. 12, pp. 1801-1807, 2007.

[23] X. L. Lu, Y. Chen, and H. J. Jiang, "Research progress in new replaceable coupling beams," Journal of Earthquake Engineering and Engineering Vibration, vol. 33, no. 1, pp. 9-15, 2013.

[24] X. D. Ji, D. Liu, and Y. Sun, Seismic performance assessment of a hybrid coupled wall system with replaceable steel coupling beams versus traditional $R C$ coupling beams. Earthquake Engineering \& Structural Dynamics, 2016.

[25] H.-S. Chung, B.-W. Moon, S.-K. Lee, J.-H. Park, and K.-W. Min, "Seismic performance of friction dampers using flexure of RC shear wall system," The Structural Design of Tall and Special Buildings, vol. 18, no. 7, pp. 807-822, 2009.

[26] J. Teng, B. Ma, W. Li, H. Zhang, and D. Cao, "Pseudo-static test for coupling beam damper of coupled shear wall structure," Jianzhu Jiegou Xuebao/Journal of Building Structures, vol. 31, no. 12, pp. 92-100, 2010

[27] C. X. Mao, Z. Y. Wang, and L. Q. Zhang, "Seismic performance of RC frame-shear wall structure with novel shape memory alloy dampers in coupling beams," in Proceeding of 15 WCEE, Lisbon, Portugal, 2012.

[28] H. Kumagai, K. Shimazaki, and S. Hayashi, "Restoring force characteristics of coupling beam dampers: Coupling beam dampers with low yield point steel (Part 2)," Journal of Structural and Construction Engineering, vol. 74, no. 643, pp. 1677-1684, 2009.

[29] H. Kumagai, Studies on seismic performance of high-rise buildings with RC shear walls and coupling beam dampers. Doctoral dissertation [Doctoral, thesis], Tokyo University, 2010.

[30] R. M. Lyons, C. Christopoulos, and M. S. Montgomery, "Enhancing the seismic performance of RC coupled wall highrise buildings with viscoelastic coupling dampers," in Proceeding of 15WCEE, Lisbon, Portugal, 2012.

[31] H. J. Kim, K. S. Choi, and S. H. Oh, "Comparative study on seismic performance of conventional RC coupling beams and hybrid energy dissipative coupling beams used for RC shear walls," in Proceeding of 15WCEE, Lisbon, Portugal, 2012.

[32] S. H. Oh, K. Y. Choi, H. J. Kim, and et al., "Experimental validation on dynamic response of RC shear wall systems coupled with hybrid energy dissipative devices," in Proceedings of 15 WCEE, p. 1422, Lisbon, Portugal, 2012.

[33] C. C. McDaniel and F. Seible, "Influence of inelastic tower links on cable-supported bridge response," Journal of Bridge Engineering, vol. 10, no. 3, pp. 272-280, 2005.

[34] G. A. Rassati, P. J. Fortney, and B. M. Shahrooz, "Design of innovative coupling beams for use in hybrid coupled core wall system," in Proceedings of the NSF CMMI Research and Innovation Conference, Honolulu, Hawaii, USA, 2009.

[35] G. A. Rassati, P. J. Fortney, B. M. Shahrooz, and P. W. Johnson, "Performance evaluation of innovative hybrid coupled core wall 
systems," in Proceedings of the 6th International Conference on Composite Construction in Steel and Concrete, pp. 479-492, usa, July 2008.

[36] Y. C. Kurama and Q. Shen, "Seismic design and response evaluation of unbonded post-tensioned hybrid coupled wall structures," Earthquake Engineering \& Structural Dynamics, vol. 37, no. 14, pp. 1677-1702, 2008.

[37] M. Aliaari, Development of seismic infill wall isolator subframe (SIWIS) system, Doctoral dissertation, The Pennsylvania State University, 2005.

[38] M. R. Eatherton, J. F. Hajjar, G. G. Deierlein, and et al., "Controlled rocking of steel-framed buildings with replaceable energy dissipating fuses," in The 14th World Conference on Earthquake Engineering, Beijing, China, 2008.

[39] J. J. Ajrab, G. Pekcan, and J. B. Mander, "Rocking wall-frame structures with supplemental tendon systems," Journal of Structural Engineering, vol. 130, no. 6, pp. 895-903, 2004.

[40] T. Hitaka and K. Sakino, "Cyclic tests on a hybrid coupled wall utilizing a rocking mechanism," Earthquake Engineering \& Structural Dynamics, vol. 37, no. 14, pp. 1657-1676, 2008.

[41] A. Wada, Z. Qu, H. Ito, S. Motoyui, H. Sakata, and K. Kasai, "Seismic retrofit using rocking walls and steel dampers," in Proceedings of the 2009 ATC and SEI Conference on Improving the Seismic Performance of Existing Buildings and Other Structures, pp. 1010-1021, USA, December 2009.

[42] L. A. Toranzo, J. I. Restrepo, and A. J. Carr, "Rocking confined masonry walls with hysteretic energy dissipators and shaketable validation," in Proceedings of the Proceeding of 13th World Conference on Earthquake Engineering, Vancouver, Canada, 2004.

[43] X. L. Lu, Y. J. Mao, and Y. Chen, “Test and analysis on shear walls with replaceable devices under cyclic loading for earthquake resilient structures," in Proceedings of the 9th CUEE and 4th ACEE Joint Conference, Tokyo, Japan, 2012.

[44] X. L. Lu, Y. Y. Mao, and Y. Cheng, "Earthquake resilience of tall buildings using replaceable energy dissipation members," in Proceedings of the Tenth U.S. National Conference on Earthquake Engineering Frontiers of Earthquake Engineering (10NCEE, Anchorage, Alaska, USA, 2014.

[45] Y. Lu, M. Panagiotou, and I. Koutromanos, “Three-dimensional beam-truss model for reinforced concrete walls and slabs part 1: modeling approach, validation, and parametric study for individual reinforced concrete walls," Earthquake Engineering \& Structural Dynamics, vol. 45, no. 9, pp. 1495-1513, 2016.

[46] X. Lu, Y. Mao, Y. Chen, J. Liu, and Y. Zhou, "New structural system for earthquake resilient design," Journal of Earthquake and Tsunami, vol. 7, no. 3, Article ID 1350013, 2013.

[47] Z.-H. Deng, Q. Lin, Q. Hu, Z.-M. Pan, and D.-X. Xu, “Test for aseismic behavior of new steel truss coupling beams," Zhendong yu Chongji, vol. 31, no. 1, pp. 76-81, 2012.

[48] X. Li, Lu. HL, and YL. She, "Experimental study on seismic behavior of replaceable steel truss coupling beams with energydissipating devices," Journal of Building Structures (Supplement, vol. 31, no. 1, pp. 389-394, 2013.

[49] X. Ji, Y. Wang, Q. Ma, and T. Okazaki, "Cyclic Behavior of Very Short Steel Shear Links," Journal of Structural Engineering, vol. 142, no. 2, p. 04015114, 2016.

[50] X. Ji, Y. Wang, Q. Ma, and T. Okazaki, "Cyclic Behavior of Replaceable Steel Coupling Beams," Journal of Structural Engineering, vol. 143, no. 2, p. 04016169, 2017.
[51] W. Y. Loo, P. Quenneville, and N. Chouw, "A numerical study of the seismic behaviour of timber shear walls with slip-friction connectors," Engineering Structures, vol. 34, pp. 233-243, 2012.

[52] M. J. N. Priestley and J. R. Tao, "Seismic response of precast prestressed concrete frames with partially debonded tendons," PCI journal, vol. 38, no. 1, pp. 58-69, 1993.

[53] M. J. N. Priestley and G. A. MacRae, "Seismic tests of precast beam-to-column joint subassemblages with unbonded tendons," PCI journal, vol. 41, no. 1, pp. 64-80, 1996.

[54] B. G. Morgen and Y. C. Kurama, "A friction damper for posttensioned precast concrete moment frames," Precast Concrete Institute journal, vol. 49, no. 4, pp. 112-133, 2004.

[55] Y. Kurama, S. Pessiki, R. Sause, and L.-W. Lu, "Seismic behavior and design of unbonded post-tensioned precast concrete walls," PCI journal, vol. 44, no. 3, pp. 72-89, 1999.

[56] S. Sritharan, S. Aaleti, and D. Thomas, Seismic analysis and design of precast concrete jointed wall systems. ISU-ERI-Ames Report ERI-07404, Iowa State University, 2007.

[57] J. M. Ricles, R. Sause, M. M. Garlock, and C. Zhao, "Posttensioned seismic-resistant connections for steel frames," Journal of Structural Engineering, vol. 127, no. 2, pp. 113-121, 2001.

[58] J. Teng, B. Ma, W. Li et al., "Seismic simulation test for coupling beam damper of coupled shear wall structure," Jianzhu Jiegou Xuebao/Journal of Building Structures, vol. 31, no. 12, pp. 101-107, 2010.

[59] H. Kumagai, "Earthquake response of a high-rise building with reinforced concrete shear walls and coupling beam dampers," Research report of Shimizu Corporation, 2010.

[60] M. Montgomery and C. Christopoulos, "Experimental validation of viscoelastic coupling dampers for enhanced dynamic performance of high-rise buildings," Journal of Structural Engineering (United States), vol. 141, no. 5, Article ID 4014145, 2015.

[61] P. M. Clayton, Self-centering steel plate shear walls: Development of design procedure and evaluation of seismic performance, University of Washington, Department of Civil and Environmental Engineering, Seattle, Wash, USA, 2010.

[62] C. P. Devereux, T. J. Holden, and A. H. Buchanan, "NMIT arts media building-damage mitigation using post-tensioned timber walls," in Proceedings of the 9th Pacific Conference on Earthquake Engineering, Auckland, New Zealand, 2011.

[63] C.-T. Cheng, "Shaking table tests of a self-centering designed bridge substructure," Engineering Structures, vol. 30, no. 12, pp. 3426-3433, 2008.

[64] R. Sause, J. M. Ricles, D. Roke, and et al., "Self-centering seismic resistant steel concentrically-braced frames," in Proceedings of 5th International Conference on Behaviour of Steel Structures in Seismic Areas, pp. 85-90, Yokohama, Taylor, 2006.

[65] M. M. Garlock, R. Sause, and J. M. Ricles, "Behavior and design of posttensioned steel frame systems," Journal of Structural Engineering, vol. 133, no. 3, pp. 389-399, 2007.

[66] Y.-C. Lin, J. Ricles, R. Sause, and C.-Y. Seo, "Earthquake simulations on a self-centering steel moment resisting frame with web friction devices," in Proceedings of the 2009 Structures Congress - Don't Mess with Structural Engineers: Expanding Our Role, pp. 1364-1373, USA, May 2009.

[67] Y. Kurama, Q. Shen, and B. Weldon, "Coupling of RC walls using unbonded post-tensioning: application in hybrid construction," in Proceedings of the 13th World Conference on Earthquake Engineering, Vancouver, B.C., Canada, 2004.

[68] Y. C. Kurama, B. D. Weldon, and Q. Shen, "Experimental evaluation of posttensioned hybrid coupled wall subassemblages," 
Journal of Structural Engineering, vol. 132, no. 7, Article ID 002607QST, pp. 1017-1029, 2006.

[69] Q. Shen and Y. Kurama, "Nonlinear behavior of posttensioned hybrid coupled wall subassemblages," Journal Structural Engineering, vol. 128, no. 10, pp. 1290-1300, 2002.

[70] Y. C. Kurama and Q. Shen, "Posttensioned hybrid coupled walls under lateral loads," Journal of Structural Engineering, vol. 130, no. 2, pp. 297-309, 2004.

[71] Q. Shen, Y. C. Kurama, and B. D. Weldon, "Seismic design and analytical modeling of posttensioned hybrid coupled wall subassemblages," Journal of Structural Engineering, vol. 132, no. 7, Article ID 001607QST, pp. 1030-1040, 2006.

[72] A. M. Memari and M. Aliaari, "Seismic infill wall isolator sub frame (SIWIS) system for use in buildings," Proc., ATC-17-2 Seismic on Response Modification Technologies for PerformanceBased Design, Los Angeles, Calif, USA, 2002.

[73] A. M. Memari, "Recent developments in seismic isolation systems for masonry infill and brick veneer walls," in Proceedings of the Building Integration Solutions: Proceedings of the Architectural Engineering 2003 Conference, pp. 258-262, usa, September 2003.

[74] M. Aliaari and A. M. Memari, "Experimental evaluation of a sacrificial seismic fuse device for masonry infill walls," Journal of Architectural Engineering, vol. 13, no. 2, pp. 111-125, 2007.

[75] A. M. Memari and M. Aliaari, "Analysis of masonry infilled steel frames with seismic isolator subframes," Engineering Structures, vol. 27, no. 4, pp. 487-500, 2005.

[76] A. M. Memari and M. Aliaari, "Pushover analysis of masonry infilled steel frames with seismic infill wall isolator subframe (SIWIS) system," pp. 191-202.

[77] M. Aliaari and A. M. Memari, "Development of a seismic design approach for infill walls equipped with structural fuse," The Open Civil Engineering Journal, vol. 6, no. 1, pp. 249-263, 2012.

[78] C. Christopoulos, A. Filiatrault, and B. Folz, "Seismic response of self-centring hysteretic SDOF systems," Earthquake Engineering \& Structural Dynamics, vol. 31, no. 5, pp. 1131-1150, 2002.

[79] Y. Funato, Y. P. Sun, T. Takeuchi, and G. C. Cai, "Modeling and Application of Bond Characteristic of High-strength Reinforcing Bar with Spiral Grooves," in Proceedings of the Cai GC. Modeling and Application of Bond Characteristic of Highstrength Reinforcing Bar with Spiral Grooves. Proceedings of the Japan Concrete Institute, vol. 34, pp. 157-162.

[80] J. H. Wang, T. Takeuchi, T. Koyama, and Y. P. Sun, "Seismic behavior of circular fly ash concrete beam-column reinforced by SBPDN rebars and steel-plate jacketing," in Proceedings of the Japan Concrete Institute, vol. 37, pp. 93-198, 2015.

[81] G. W. Housner, "The behavior of inverted pendulum structures during earthquakes," Bulletin of the Seismological Society of America, vol. 53, no. 2, pp. 403-417, 1963.

[82] A. A. Hukelbridge and R. W. Clough, "Preliminary experimental study of seismic uplift of a steel frame," Tech. Rep., Berkley, University of California, Berkeley, Calif, USA, 1977.

[83] A. A. Hukelbridge, "Earthquake simulation tests of a nine story steel frame with columns allowed to uplift," Tech. Rep., Berkeley, University of California, Berkeley, Calif, USA, 1977.

[84] M. J. N. Priestley, R. J. Evison, and A. J. Carr, "Seismic response of structures free to rock on their foundation," Bulletin of the New Zealand Society for Earthquake Engineering, vol. 11, no. 3, pp. 141-150, 1978.

[85] J. W. Meek, "Dynamic response of tipping core buildings," Earthquake Engineering \& Structural Dynamics, vol. 6, no. 5, pp. 437-454, 1978.
[86] C.-S. Yim, A. K. Chopra, and J. Penzien, "Rocking response of rigid blocks to earthquakes," Earthquake Engineering \& Structural Dynamics, vol. 8, no. 6, pp. 565-587, 1980.

[87] M. Aslam, W. G. Godden, and D. T. Scalise, "Earthquake rocking response of rigid bodies," Journal of the Structural Division, vol. 106, no. 2, pp. 377-392, 1980.

[88] I. N. Psycharis and P. C. Jennings, "Rocking of slender rigid bodies allowed to uplift," Earthquake Engineering \& Structural Dynamics, vol. 11, no. 1, pp. 57-76, 1983.

[89] M. J. N. Priestley, F. Seible, and G. M. Calvi, Seismic Design and Retrofit of Bridges, John Wiley \& Sons, New York, NY, USA, 1996.

[90] J. B. Mander and C. T. Cheng, "Seismic resistance of bridge piers based on damage avoidance design," Technical Report MCEER97-0014, Buffalo: University at Buffalo, The State University of New York. Multidisciplinary Center for Earthquake Engineering Research, 1997.

[91] M. Mashal, S. White, and A. Palermo, "Concepts and developments for accelerated bridge construction and dissipative controlled rocking," in Proceedings of the 15 WCEE, Lisboa, Portugal, 2012.

[92] H. Roh, Seismic behavior of structures using rocking columns and viscous dampers, Buffalo, University at Buffalo, The State University of New York. Department of Civil, Structural and Environmental Engineering, 2007.

[93] H. Roh and A. M. Reinhorn, "Nonlinear static analysis of structures with rocking columns," Journal of Structural Engineering, vol. 136, no. 5, pp. 532-542, 2010.

[94] H. Roh and A. M. Reinhorn, "Modeling and seismic response of structures with concrete rocking columns and viscous dampers," Engineering Structures, vol. 32, no. 8, pp. 2096-2107, 2010.

[95] H. Y. Cao, P. Pan, S. J. Wu, L. P. Ye, and et al., "Experimental study of connections of frame-rocking wall system," Journal of Building Structures, vol. 33, no. 12, pp. 38-46, 2012.

[96] M. Midorikawa, T. Azuhata, T. Ishihara, and A. Wada, "Three dimensional shaking table tests on seismic response of reducedscale steel rocking frames," in Proceedings of the 3rd International Conference on Advances in Experimental Structural Engineering, Earthquake Engineering Research Center, San Francisco, USA, 2009.

[97] M. Midorikawa, T. Ishihara, T. Azuhata, and et al., Seismic Behavior of Steel Rocking Frames by Three-Dimensional Shaking Table Tests, 7 CUEE \& 5 IC, Tokyo Institute of Technology, Tokyo, Japan, 2010.

[98] X. Ma, G. Deierlein, H. Krawinkler, M. Eatherton, and et al., "Large-scale shaking table test of steel braced frame with controlled rocking and energy dissipating fuses," in Proceedings of the 9th US National and 10th Canadian Conference on Earthquake Engineering, Canadian Association for Earthquake Engineering, Ottawa, Canada, 2010.

[99] M. R. Eatherton, J. F. Hajjar, and G. Deierlein, "Hybrid simulation testing of a controlled rocking steel braced frame system," in Proceedings of the 9th US National and 10th Canadian Conference on Earthquake Engineering, Canadian Association for Earthquake Engineering, Ottawa, Canada, 2010.

[100] D. L. Anderson, "Effect of foundation rocking on the seismic response of shear walls," Canadian Journal of Civil Engineering, vol. 30, no. 2, pp. 360-365, 2003.

[101] S. Gajan and B. L. Kutter, "Capacity, settlement, and energy dissipation of shallow footings subjected to rocking," Journal of Geotechnical and Geoenvironmental Engineering, vol. 134, no. 8, pp. 1129-1141, 2008. 
[102] S. Gajan, Physical and numerical modeling of nonlinear cyclic load-deformation behavior of shallow foundations supporting rocking shear walls. Davis, Calif, USA, Dept. of Civil and Environmental Engineering, Univ. of California, 2006.

[103] S. Gajan and B. L. Kutter, "Effects of moment-to-shear ratio on combined cyclic load-displacement behavior of shallow foundations from centrifuge experiments," Journal of Geotechnical and Geoenvironmental Engineering, vol. 135, no. 8, pp. 1044$1055,2009$.

[104] Y. Lu, "Inelastic behaviour of RC wall-frame with a rocking wall and its analysis incorporating 3-D effect," The Structural Design of Tall and Special Buildings, vol. 14, no. 1, pp. 15-35, 2005.

[105] L. Wiebe and C. Christopoulos, "Mitigation of higher mode effects in base-rocking systems by using multiple rocking sections," Journal of Earthquake Engineering, vol. 13, no. 1, pp. 83-108, 2009.

[106] L. Wiebe, Mitigation of higher mode effects in self-centering walls by using multiple rocking sections [Master, thesis], Master dissertation, Università degli Studi di Pavia, 2008.

[107] K. J. Mulligan, J. G. Chase, J. B. Mander, and et al., "Hybrid experimental analysis of semi-active rocking wall systems," in Proceedings of New Zealand Society of Earthquake Engineering (NZSEE), Napier, New Zealand, 2006.

[108] D. Marriott, S. Pampanin, and D. Bull, "Improving the seismic performance of existing reinforced concrete buildings using advanced rocking wall solutions," in Proceedings of New Zealand Society of Earthquake Engineering (NZSEE), Palmerston North, New Zealand, 2007.

[109] L. A. Toranzo, A. Carr J, and J. I. Restrepo, "Displacement based design of rocking walls incorporating hysteretic energy dissipators," Passive Energy Dissipation and Active Control of Vibration of Structures, 2001.

[110] L. A. Toranzo, The use of rocking walls in confined masonry structures: a performance-based approach [Doctoral, thesis], Department of Civil Engineering, University of Canterbury, New Zealand, 2002.

[111] L. A. Toranzo, J. I. Restrepo, J. B. Mander, and A. J. Carr, "Shaketable tests of confined-masonry rocking walls with supplementary hysteretic damping," Journal of Earthquake Engineering, vol. 13, no. 6, pp. 882-898, 2009.

[112] C. Bora, M. G. Oliva, S. D. Nakaki, and R. Becker, "Development of a precast concrete shear-wall system requiring special code acceptance," PCI journal, vol. 52, no. 1, pp. 122-135, 2007.

[113] S. Kishiki and A. Wada, "Shaking table test on controlled rocking frame of wooden structures," in 7CUEE \& 5ICEE, pp. 1091-1095, Tokyo Institute of Technology, Tokyo, Japan, 2010.

[114] G. Nielsen M, I. Almufti, and S. A. Mahin, "Performance of rocking core walls in tall buildings under severe seismic motions," in Proceedings of the 9th US National and 10th Canadian Conference on Earthquake Engineering, Ottawa, Canada, 2010.

[115] Y. Zhou, R. Li, and X. L. Lu, "Earthquake-resilient tall buildings using rocking walls," in Proceeding of 15 WCEE, Lisboa, Portugal, 2012.

[116] G. S. Cheok and H. S. Lew, "Model Precast Concrete Beam-toColumn Connections Subject to Cyclic Loading," PCI journal, vol. 38, no. 4, pp. 80-92, 1993.

[117] M. T. El-Sheikh, R. Sause, S. Pessiki, and L.-W. Lu, "Seismic behavior and design of unbonded post-tensioned precast concrete frames," PCI journal, vol. 44, no. 3, pp. 54-71, 1999.
[118] X. Cai, S. Meng, and W. Sun, "Experimental study on behaviors of beam-column connections for self-centering post-tensioned precast frame," Tumu Gongcheng Xuebao/China Civil Engineering Journal, vol. 45, no. 12, pp. 29-37, 2012.

[119] X. L. Lu, Y. Cui, and J. J. Liu, "Shaking table test of a self-centering reinforced concrete frame," Journal of Building Structures, vol. 30, no. 9, pp. 31-35, 2014.

[120] Y. Kurama, S. Pessiki, R. Sause Lu, and et al., "Analytical modeling and lateral load behavior of unbonded post-tensioned precast concrete Walls," Tech. Rep., Department of Civil and Environmental Engineering, Lehigh University, Bethlehem, PA, USA, 1996.

[121] Y. C. Kurama, R. Sause, S. Pessiki, and et al., "Seismic design and response evaluation of unbonded post-tensioned precast concrete walls," Tech. Rep., Department of Civil and Environmental Engineering, Lehigh University, 1997.

[122] Y. Kurama, R. Sause, S. Pessiki, and L.-W. Lu, "Lateral load behavior and seismic design of unbonded post-tensioned precast concrete walls," ACI Structural Journal, vol. 96, no. 4, pp. 622-632, 1999.

[123] Y. C. Kurama, "Seismic design of unbonded post-tensioned precast concrete walls with supplemental viscous damping," ACI Structural Journal, vol. 97, no. 4, pp. 648-658, 2000.

[124] Y. C. Kurama, R. Sause, S. Pessiki, and L.-W. Lu, "Seismic response evaluation of unbonded post-tensioned precast walls," ACI Structural Journal, vol. 99, no. 5, pp. 641-651, 2002.

[125] F. J. Perez, S. Pessiki, and R. Sause, "Experimental and analytical lateral load response of unbonded post tensioned precast concrete walls," in Center for Advanced Technology for Large Structural Systems (ATLSS). No. 04-11, Lehigh Univ, Bethlehem, PA, USA, 2004.

[126] F. J. Perez, R. Sause, and S. Pessiki, "Analytical and experimental lateral load behavior of unbonded posttensioned precast concrete walls," Journal of Structural Engineering, vol. 133, no. 11, pp. 1531-1540, 2007.

[127] B. J. Smith, Y. C. Kurama, and M. J. McGinnis, "Design and measured behavior of a hybrid precast concrete wall specimen for seismic regions," Journal of Structural Engineering, vol. 137, no. 10, pp. 1052-1062, 2011.

[128] B. J. Smith, Y. C. Kurama, and M. J. McGinnis, "Behavior of precast concrete shear walls for seismic regions: comparison of hybrid and emulative specimens," Journal of Structural Engineering, vol. 139, no. 11, pp. 1917-1927, 2013.

[129] T. Holden, J. Restrepo, and J. B. Mander, "Seismic performance of precast reinforced and prestressed concrete walls," Journal of Structural Engineering, vol. 129, no. 3, pp. 286-296, 2003.

[130] J. I. Restrepo and A. Rahman, "Seismic performance of selfcentering structural walls incorporating energy dissipators," Journal of Structural Engineering, vol. 133, no. 11, pp. 1560-1570, 2007.

[131] D. Marriott, S. Pampanin, D. Bull, and A. Palermo, "Dynamic testing of precast, post-tensioned rocking wall systems with alternative dissipating solutions," Bulletin of the New Zealand Society for Earthquake Engineering, vol. 41, no. 2, pp. 90-103, 2008.

[132] G. Mannasa and S. Reddy, "A study on analysis and design of precast concrete wall system," in Proceedings of the International Journal of Advanced Technology and Innovative Research, vol. 8, pp. 2707-2712, 2016.

[133] L. Panian, M. Steyer, and S. Tipping, "Post-Tensioned concrete walls for seismic resistance," Journal of the Post-tersioning Institute, vol. 5, no. 1, p. 12, 2007. 
[134] L. Panian, M. Steyer, and S. Tipping, "Post-Tensioned shotcrete shear walls," in Post-Tensioned shotcrete shear walls, vol. 29, Farmington Hills, Mich, USA, 2007.

[135] M. Stevenson, L. Panian, and M. Korolyk, "Post-tensioned concrete walls and frames for seismic resistance - a case study of the David Brower Center," in Proceedings of the SEAOC Annual Convention, Hawaii, USA, 2008.

[136] M. A. Rahman and S. Sritharan, "An evaluation of forcebased design vs. direct displacement-based design of jointed precast post-tensioned wall systems," Earthquake Engineering and Engineering Vibration, vol. 5, no. 2, pp. 285-296, 2006.

[137] D. Pennucci, "Displacement-based design of precast walls with additional dampers," in Italy, European School for Advanced Studies in Reduction of Seismic Risk, ROSE School, University of Pavia, 2008.

[138] D. Pennucci, G. M. Calvi, and T. J. Sullivan, "Displacementbased design of precast walls with additional dampers," Journal of Earthquake Engineering, vol. 13, no. 1, pp. 40-65, 2009.

[139] S. Aaleti and S. Sritharan, "A simplified analysis method for characterizing unbonded post-tensioned precast wall systems," Engineering Structures, vol. 31, no. 12, pp. 2966-2975, 2009.

[140] B. Erkmen and A. E. Schultz, "Self-centering behavior of unbonded, post-tensioned precast concrete shear walls," Journal of Earthquake Engineering, vol. 13, no. 7, pp. 1047-1064, 2009.

[141] K. M. Twigden, R. S. Henry, and Q. T. Ma, "Dynamic testing of post-tensioned rocking walls," in Proceedings of the Proceeding of 15th World Conference on Earthquake Engineering, Lisbon, Portugal, 2012.

[142] H.-J. Kim and C. Christopoulos, "Friction damped posttensioned self-centering steel moment-resisting frames," Journal of Structural Engineering, vol. 134, no. 11, pp. 1768-1779, 2008.

[143] M. Wolski, J. M. Ricles, and R. Sause, "Experimental study of a self-centering beam-column connection with bottom flange friction device," Journal of Structural Engineering, vol. 135, no. 5, pp. 479-488, 2009.

[144] P. Rojas, J. M. Ricles, and R. Sause, "Seismic performance of post-tensioned steel moment resisting frames with friction devices," Journal of Structural Engineering, vol. 131, no. 4, pp. 529-540, 2005.

[145] R. Sause, J. M. Ricles, and Y. Lin, "Self-centering damage-free seismic-resistant steel frame systems," in 7 CUEE \& 5ICEE, pp. 39-48, Tokyo Institute of Technology, Tokyo, Japan, 2010.

[146] T. B. Winkley, Self-centering steel plate shear walls. Large scale experimental investigation, University of Washington, Department of Civil and Environmental Engineering, Seattle, Wash, USA, 2011.

[147] P. M. Clayton, T. B. Winkley, J. W. Berman, and L. N. Lowes, "Experimental investigation of self-centering steel plate shear walls," Journal of Structural Engineering (United States), vol. 138, no. 7, pp. 952-960, 2012.

[148] D. M. Dowden, R. Purba, and M. Bruneau, "Behavior of selfcentering steel plate shear walls and design considerations," Journal of Structural Engineering (United States), vol. 138, no. 1, pp. 11-21, 2012.

[149] G. D. Wight, J. M. Ingham, and M. J. Kowalsky, "Shaketable testing of rectangular post-tensioned concrete masonry walls," ACI Structural Journal, vol. 103, no. 4, pp. 587-595, 2006.

[150] G. D. Wight, M. J. Kowalsky, and J. M. Ingham, "Shake table testing of posttensioned concrete masonry walls with openings," Journal of Structural Engineering, vol. 133, no. 11, pp. 1551-1559, 2007.
[151] P. T. Laursen and J. M. Ingham, "In-plane Response of Posttensioned Concrete Masonry," Journal of the Structural Engineering Society of New Zealand, vol. 12, no. 2, pp. 21-39, 1999.

[152] P. T. Laursen and J. M. Ingham, "Structural Testing of SingleStorey Post-Tensioned Concrete Masonry Walls," Journal of the Masonry Society, vol. 19, no. 1, pp. 69-82, 2001.

[153] P. T. Laursen and J. M. Ingham, "Structural Testing of Enhanced Post-Tensioned Concrete Masonry Walls," ACI Structural Journal, vol. 101, no. 6, pp. 852-862, 2004.

[154] P. T. Laursen and J. M. Ingham, "Structural testing of large-scale posttensioned concrete masonry walls," Journal of Structural Engineering, vol. 130, no. 10, pp. 1497-1505, 2004.

[155] P. T. Laursen, "Seismic performance of prestressed concrete masonry walls incorporating energy dissipators," in Proceedings of the The 14th World Conference on Earthquake Engineering, Beijing, China, 2008.

[156] R. Hassanli, M. A. Elgawady, and J. E. Mills, "Experimental Investigation of In-Plane Cyclic Response of Unbonded Posttensioned Masonry Walls," Journal of Structural Engineering (United States), vol. 142, no. 5, Article ID 04015171, 2016.

[157] R. Hassanli, Behavior of unbonded post-tentioned masonry walls. Doctoral dissertation, University of South Australia, 2015.

[158] R. Hassanli, M. A. ElGawady, and J. E. Mills, "Strength and seismic performance factors of posttensioned masonry walls," Journal of Structural Engineering, vol. 141, no. 11, 2015.

[159] J. Abouzar, R. G. Mohammad, A. B. Habib, and et al., Seismic performance and damage incurred by monolithic concrete selfcentering rocking walls under the effect of axial stress ratio. Bulletin Earthquake Engineering, 2017.

[160] R. Hassanli, M. A. ElGawady, and J. E. Mills, "In-plane flexural strength of unbonded post-tensioned concrete masonry walls," Engineering Structures, vol. 136, pp. 245-260, 2017.

[161] A. Palermo, S. Pampanin, and G. M. Calvi, "Concept and development of hybrid solutions for seismic resistant bridge systems," Journal of Earthquake Engineering, vol. 9, no. 6, pp. 899-921, 2005.

[162] EI. Mohanmed, SL. Ahmad, and MD. Haitham, "Seismic behavior of segmented frames," in Proceedings of the 9th US National and 10th Canadian Conference on Earthquake Engineering, Toronto, Canada, 2010.

[163] S. L. Ahmad, Seismic performance of self-centering frames composed of precast post-tensioned concrete encased in FRP tubes; Master dissertation [Master, thesis], 2009.

[164] M. Elgawady, A. J. Booker, and H. M. Dawood, "Seismic behavior of posttensioned concrete-filled fiber tubes," Journal of Composites for Construction, vol. 14, no. 5, pp. 616-628, 2010.

[165] M. D. Haitham, Seismic behavior and design of segment precast post-tensioned concrete piers. Master dissertation [Master, thesis], Washington State University, 2010.

[166] M. Ayman and M. A. EIGawady, "Damage-resistant segmental double-skin bridge column with replaceable energy dissipaters," in The Sixth International Conference on Structural Engineering, Mechanics and Computation, Aapril 2016, M. Ayman, M. A. EIGawady, Damage-resistant segmental double-skin bridge column with replaceable energy dissipaters, The Sixth International Conference on Structural Engineering, Mechanics and Computation, April 2016.

[167] S. Ichikawa, H. Matsuzaki, A. Moustafa, M. A. Elgawady, and K. Kawashima, "Seismic-resistant bridge columns with ultrahighperformance concrete segments," Journal of Bridge Engineering, vol. 21, no. 9, Article ID 04016049, 2016. 
[168] J. Guo, K. G. Xin, M. H. He, and L. Hu, Experimental study and analysis on the seismic performance of a self-centering bridge pier. Engineering Mechanics (Suppl I), 29, 34, 2012.

[169] M. H. He, K. G. Xin, and J. Guo, "Local stability study of new bridge piers with self-centering joins," Engineering Mechanics, vol. 29, no. 4, pp. 122-127, 2012.

[170] H. Dong, X. Du, Q. Han, H. Hao, K. Bi, and X. Wang, "Performance of an innovative self-centering buckling restrained brace for mitigating seismic responses of bridge structures with double-column piers," Engineering Structures, vol. 148, pp. 4762, 2017.

[171] N. Gonner, N. B. Chancellor, R. Sause, J. M. Ricles, and D. Roke, "Experimental Setup, and Testing of Self-Centering Steel Concentrically-Braced Frame Test Structure," Tech. Rep., Lehigh University, Bethlehem, PA, USA, 2010.

[172] D. J. Miller, L. A. Fahnestock, and M. R. Eatherton, "Development and experimental validation of a nickel-titanium shape memory alloy self-centering buckling-restrained brace," Engineering Structures, vol. 40, pp. 288-298, 2012.

[173] M. Pollino and M. Bruneau, "Seismic testing of a bridge steel truss pier designed for controlled rocking," Journal of Structural Engineering, vol. 136, no. 12, pp. 1523-1532, 2010.

[174] X. Ma, H. Krawinkler, and G. Deierlein, Seismic Design, Simulation and Shake Table Testing of Self-Centering Braced Frame with Controlled Rocking and Energy Dissipating Fuses, Stanford University: Stanford, CA, USA, 2011.

[175] Z. Sun and C. C. Chang, "Structural damage assessment based on wavelet packet transform," Journal of Structural Engineering, vol. 128, no. 10, pp. 1354-1361, 2002.

[176] A. Maurya and M. R. Eatherton, "Self-centering beams with resilient seismic performance," in Proceedings of the Structures Congress 2014, pp. 2442-2453, USA, April 2014.

[177] A. Palermo, S. Pampanin, and D. Marriott, "Design, modeling, and experimental response of seismic resistant bridge piers with posttensioned dissipating connections," Journal of Structural Engineering, vol. 133, no. 11, pp. 1648-1661, 2007.

[178] M. A. Rahman and S. Sritharan, "Performance-based seismic evaluation of two five-story precast concrete hybrid frame buildings," Journal of Structural Engineering, vol. 133, no. 11, pp. 1489-1500, 2007.

[179] T. Takamatsu, H. Tamai, T. Yamanishi, and A. Matsuo, "Selfcentering performance of non-slip-type exposed column base," in Proceedings of the 5th International Conference on Behaviour of Steel Structures in Seismic Areas - Stessa 2006, pp. 357-362, jpn, August 2006.

[180] X. Ma, E. Borchers, A. Peña, H. Krawinkler, and G. Deierlein, Design and Behavior of Steel Shear Plates with Openings as Energy-Dissipating Fuses, Stanford University, Stanford, CA, USA, 2010.

[181] M. Midorikawa, T. Azuhata, T. Ishihara, and A. Wada, "Shaking table tests on seismic response of steel braced frames with column uplift," Earthquake Engineering \& Structural Dynamics, vol. 35, no. 14, pp. 1767-1785, 2006.

[182] A. Wada, S. Yamada, O. Fukuta, and M. Tanigawa, "Passive Controlled Slender Structures Having Special Devises at Column Connections," in Proceedings of the 7th International Seminar on Seismic Isolation, Passive Energy Dissipation and Active Control of Vibrations of Structures, Assisi, Italy, 2001.

[183] M. M. Garlock, J. M. Ricles, and R. Sause, "Experimental studies of full-scale posttensioned steel connections," Journal of Structural Engineering, vol. 131, no. 3, pp. 438-448, 2005.
[184] G. Vasdravellis, T. L. Karavasilis, and B. Uy, "Large-scale experimental validation of steel posttensioned connections with web hourglass pins," Journal of Structural Engineering (United States), vol. 139, no. 6, pp. 1033-1042, 2013.

[185] M. Wolski, J. M. Ricles, and R. Sause, "Seismic resistant selfcentering steel moment resisting frames with bottom flange friction devices," in Proceedings of the 5th International Conference on the Behavior of Steel Structures in Seismic Areas (STESSA '06), pp. 481-487, Yokohama, Japan, August 2006.

[186] Y.-C. Lin, R. Sause, and J. Ricles, "Seismic performance of a large-scale steel self-centering moment-resisting frame: MCE hybrid simulations and quasi-static pushover tests," Journal of Structural Engineering (United States), vol. 139, no. 7, pp. 12271236, 2013.

[187] C. Christopoulos, R. Tremblay, H.-J. Kim, and M. Lacerte, "Selfcentering energy dissipative bracing system for the seismic resistance of structures: Development and validation," Journal of Structural Engineering, vol. 134, no. 1, pp. 96-107, 2008.

[188] R. Trmblay, L. P. Poirier, N. Bouaanani, M. Leclerc, and V. Rene, "Innovative viscously damped rocking braced steel frames," in Proceedings of the Proceeding of 14 WCEE, Beijing, China, 2008.

[189] G. Wight, Seismic performance of a post-tensioned concrete masonry wall system [Ph.D. thesis], University of Auckland, New Zealand, 2006, Ph.D dissertation.

[190] D. Ryu, A. C. Wijeyewickrema, M. A. Elgawady, and M. A. K. M. Madurapperuma, "Effects of tendon spacing on in-plane behavior of posttensioned masonry walls," Journal of Structural Engineering, vol. 140, no. 4, Article ID 4013096, 2014.

[191] R. S. Henry, S. Sritharan, and J. M. Ingham, "Finite element analysis of the PreWEC self-centering concrete wall system," Engineering Structures, vol. 115, pp. 28-41, 2016.

[192] H. A. Spieth, A. J. Carr, and A. G. Murahidy, "Modelling of post-tensioned precast reinforced concrete frame structures with rocking beam-column connections," in Proceedings of the NZSEE Conference, Rotorua, New Zealand, 2004.

[193] C. Li, H. Hao, and K. Bi, "Numerical study on the seismic performance of precast segmental concrete columns under cyclic loading," Engineering Structures, vol. 148, pp. 373-386, 2017.

[194] R. Hassanli, M. A. ElGawady, and J. E. Mills, "Force-displacement behavior of unbonded post-tensioned concrete walls," Engineering Structures, vol. 106, pp. 495-505, 2016.

[195] A. Madan, A. M. Reinhorn, and J. B. Mander, "Fiber-element model of posttensioned hollow block masonry shear walls under reversed cyclic lateral loading," Journal of Structural Engineering, vol. 134, no. 7, pp. 1101-1114, 2008.

[196] D. Kalliontzis and A. E. Schultz, "Characterizing the In-Plane Rocking Response of Masonry Walls with Unbonded Posttensioning," Journal of Structural Engineering (United States), vol. 143, no. 9, Article ID 04017110, 2017.

[197] D. J. Thomas and S. Sritharan, "An evaluation of seismic design guidelines proposed precast jointed wall systems," ISU-ERIAmes Rep ERI-04643, Dept. of Civil, Construction, and Environmental Engineering, Iowa State Univ, 2004.

[198] M. R. Eatherton and J. F. Hajjar, "Residual drifts of self-centering systems including effects of ambient building resistance," Earthquake Spectra, vol. 27, no. 3, pp. 719-744, 2011.

[199] C. Christopoulos, S. Pampanin, and M. J. N. Priestley, "Performance-based seismic response of frame structures including residual deformations, part I: single-degree of freedom systems," Journal of Earthquake Engineering, vol. 7, no. 1, pp. 97-118, 2003. 
[200] S. Pampanin, C. Christopoulos, and M. J. N. Priestley, "Performance-based seismic response of frame structures including residual deformations. Part II: multi-degree of freedom systems," Journal of Earthquake Engineering, vol. 7, no. 1, pp. 119147, 2003.

[201] R. S. Henry, S. Aaleti, S. Sritharan, and J. M. Ingham, "Seismic analysis of a low-damage Precast Wall with End Columns (PreWEC) including interaction with floor diaphragms," Journal of the Structural Engineering Society New Zealand (SESOC), vol. 25, no. 1, pp. 69-81, 2012.

[202] R. S. Henry, S. Sritharan, and J. M. Ingham, "Residual drift analyses of realistic self-centering concrete wall systems," Earthquake and Structures, vol. 10, no. 2, pp. 409-428, 2016.

[203] G. A. Macrae and K. Kawashima, "Post-earthquake residual displacements of bilinear oscillators," Earthquake Engineering \& Structural Dynamics, vol. 26, no. 7, pp. 701-716, 1997.

[204] ACI Innovation Task Group 5, Requirements for Design of a Special Unbonded Post-Tensioned Precast Shear Wall Satisfying ACI ITG-5.1 (ITG 5.2-09), American Concrete Institute, Farmington Hills, MA, USA, 2009.

[205] NZS 3101, Concrete Structures Standard, Wellington, New Zealand, Standards New Zealand, 646, 2006.

[206] ACI Innovation Task Group 5, Acceptance criteria for special unbonded post-tensioned precast structural walls based on validation testing (ITG 5.1-07), American Concrete Institute, Farmington Hills, MI, USA, 2007.

[207] D. M. Dowden and M. Bruneau, "NewZ-BREAKSS: Posttensioned rocking connection detail free of beam growth," Engineering Journal, vol. 48, no. 2, pp. 153-158, 2011.

[208] C.-C. Chou and J.-H. Chen, "Seismic design and shake table tests of a steel post-tensioned self-centering moment frame with a slab accommodating frame expansion," Earthquake Engineering \& Structural Dynamics, vol. 40, no. 11, pp. 1241-1261, 2011.

[209] C.-C. Chou and J.-H. Chen, "Development of floor slab for steel post-tensioned self-centering moment frames," Journal of Constructional Steel Research, vol. 67, no. 10, pp. 1621-1635, 2011.

[210] R. S. Henry, Self-centering precast concrete walls for buildings in regions with low to high seismicity. PhD thesis [Ph.D. thesis], Civil and Environmental Engineering., Auckland, University of Auckland, 2011.

[211] D. Roke, R. Sause, J. M. Ricles, and N. Gonner, Damage-free seismic-resistant self-centering steel concentrically-braced frames. Proc., STESSA 2009, Taylor \& Francis, London, 2009.

[212] M. Eatherton and J. Hajjar, "Large-scale cyclic and hybrid simulation testing and development of a controlled-rocking steel building system with replaceable fuses," Tech. Rep., Dept. of Civil and Env. Eng., Univ. of Illinois at Urbana-Champaign, 2010.

[213] L. Wiebe, Design of controlled rocking steel frames to limit higher mode effects. Doctoral dissertation, University of Toronto, 2013.

[214] L. Wiebe, C. Christopoulos, R. Tremblay, and M. Leclerc, "Mechanisms to limit higher mode effects in a controlled rocking steel frame. 1: Concept, modelling, and low-amplitude shake table testing," Earthquake Engineering \& Structural Dynamics, vol. 42, no. 7, pp. 1053-1068, 2013.

[215] L. Wiebe, C. Christopoulos, R. Tremblay, and M. Leclerc, "Mechanisms to limit higher mode effects in a controlled rocking steel frame. 2: Large-amplitude shake table testing," Earthquake Engineering \& Structural Dynamics, vol. 42, no. 7, pp. 1069-1086, 2013.
[216] E. Tahmasebi, N. B. Chancellor, R. Sause, J. M. Ricles, A. L. Joó, and G. Akbas, "Collapse Performance of Steel Self-Centering Braced Frame Systems," in In Proceedings of the 7th International Conference on Behavior of Steel Structures in Seismic Areas, pp. 9-11, Santiago, Chile, 2012.

[217] E. Tahmasebi, R. Sause, J. M. Ricles, N. B. Chancellor, and T. Akbas, "Probabilistic collapse performance assessment of selfcentering concentrically braced frames," in Proceedings of the 10th U.S. National Conference on Earthquake Engineering: Frontiers of Earthquake Engineering, NCEE 2014, usa, July 2014.

[218] G. MacRae, "Low Damage constructionSome Systems Issues," in Proceedings of the In Proceedings of the 10th International Conference on Urban Earthquake Engineering, Tokyo, Japan, 2013.

[219] D. A. Roke, A. Chandra, Q. Huang, and K. Sett, "Methodology for Life Cycle Cost Assessment of Self-Centering Concentrically Braced Frame Systems," in Proceedings of the In Proceedings of the 10th International Conference on Urban Earthquake Engineering, Tokyo, Japan, 2013.

[220] G. Deodatis, B. Ellingwood, and D. Frangopol, Safety, Reliability, Risk and Life-Cycle Performance of Structures and Infrastructures, CRC Press, 2014.

[221] M. Dyanati, Q. Huang, and D. A. Roke, "Structural and nonstructural performance evaluation of self-centering, concentrically braced frames under seismic loading," in Proceedings of the Structures Congress 2014, pp. 2393-2404, USA, April 2014.

[222] G. R. Pandey and H. Mutsuyoshi, "Seismic damage mitigation of reinforced concrete bridge piers by unbonding longitudinal reinforcements," in Proceedings of the Proceeding of 13WCEE, No.154, Vancouver, Canada, 2004.

[223] G. R. Pandey, H. Mutsuyoshi, T. Maki, and H. Uchibori, "Numerical study on seismic behavior of RC bridge piers with bond controlled reinforcement," in Proceedings of the Uchibori $H$. Numerical study on seismic behavior of RC bridge piers with bond controlled reinforcement. Proceeding of JCI, vol. 26, pp. 1207-1212, 2004.

[224] G. R. Pandey and H. Mutsuyoshi, "Seismic performance of reinforced concrete piers with bond-controlled reinforcements," ACI Structural Journal, vol. 102, no. 2, pp. 295-304, 2005.

[225] G. R. Pandey, H. Mutsuyoshi, and T. Maki, "Seismic performance of bond controlled RC columns," Engineering Structures, vol. 30, no. 9, pp. 2538-2547, 2008.

[226] M. Tanaka, F. Esaki, and M. Ono, "Hysteresis response of R/C column with high strength unbonded longitudinal reinforcing bars," in Proceedings of the Japan Concrete Institute, vol. 26, pp. 181-186, 2004.

[227] Y. P. Sun, G. C. Cai, and T. Takeshi, "Seismic behavior and performance-based design of resilient concrete columns," Applied Mechanics and Materials, vol. 438-439, pp. 1453-1460, 2013.

[228] S. M. Nakai, Y. P. Sun, and T. Takeuchi, "Effects axial load level and longitudinal steel ratio on seismic performance of RC Columns reinforced by ultra-high strength rebar," in Proceedings of the Japan Concrete Institute, pp. 33-157, 2011, [in Japanese].

[229] M. Tani, YP. Sun, and T. Fujinaga, "Experimental Study of Concrete Columns with High Resilience," in Proceedings of the Japan Concrete Institute, pp. 31-565, 2009, [in Japanese].

[230] S. Y. Kittaka, M. Tani, and Y. P. Sun, "Study on the bending-shear properties of RC Columns reinforced with ultra-high-strength rebar," in Proceedings of the Japan Concrete Institute, vol. 32, pp. 79-84, 2010. 
[231] Y. P. Sun and T. Takeuchi, "Fundamental Study of Earthquakeresilient Concrete Columns," in Proceedings of the Japan Concrete Institute, vol. 35, pp. 1501-1506, 2013, [in Japanese].

[232] G. C. Cai and Y. Sun, "Experimental Study of Seismic Performance of Circular Concrete Columns with High Yield Strength and Low Bond Strength rebars," in Proceedings of the Japan Concrete Institute, vol. 35, pp. 145-150, 2013.

[233] G. C. Cai, Seismic Performance and Evaluation of Resilient Circular Concrete Columns. Doctoral dissertation [Doctoral, thesis], Kobe University, 2014.

[234] S. Grigor, Y. Tanaka, T. Takeuchi, and Y. P. Sun, "Seismic Behavior and Assessment of Circular Concrete Columns Reinforced by Ultra-High Strength Rebars," in Proceedings of the Japan Concrete Institute, vol. 38, pp. 193-198, 2016.

[235] J. H. Wang, Seismic behavior and evaluation of concrete members made of a large quantity of fly ash. Doctoral dissertation [Doctoral, thesis], Kobe University, 2016. 


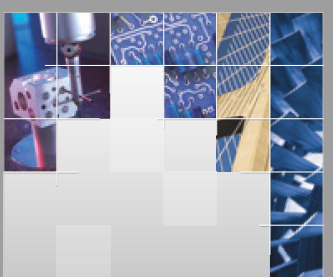

\section{Enfincering}
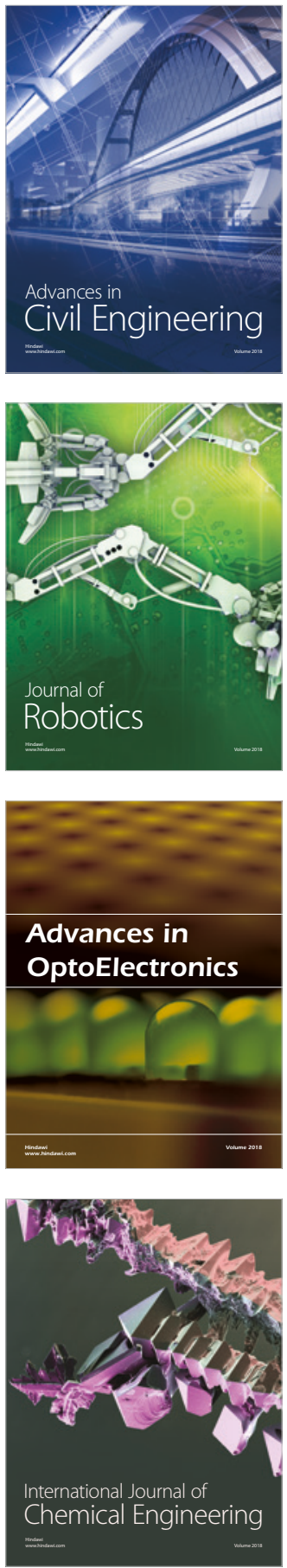

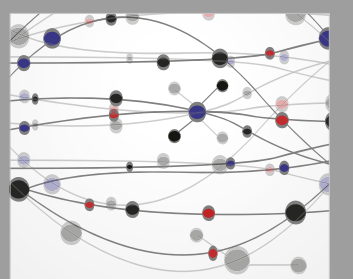

\section{Rotating \\ Machinery}

The Scientific World Journal

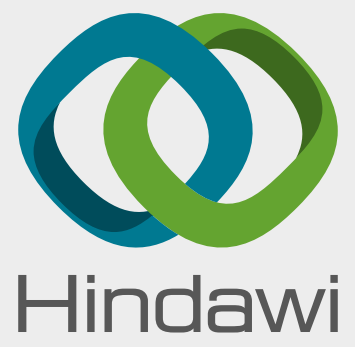

Submit your manuscripts at

www.hindawi.com
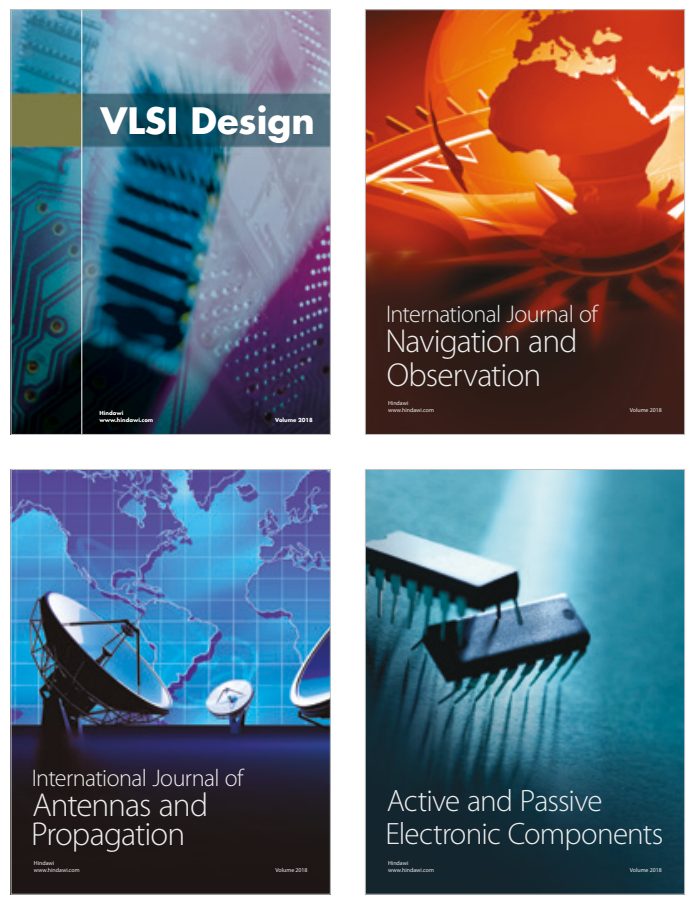
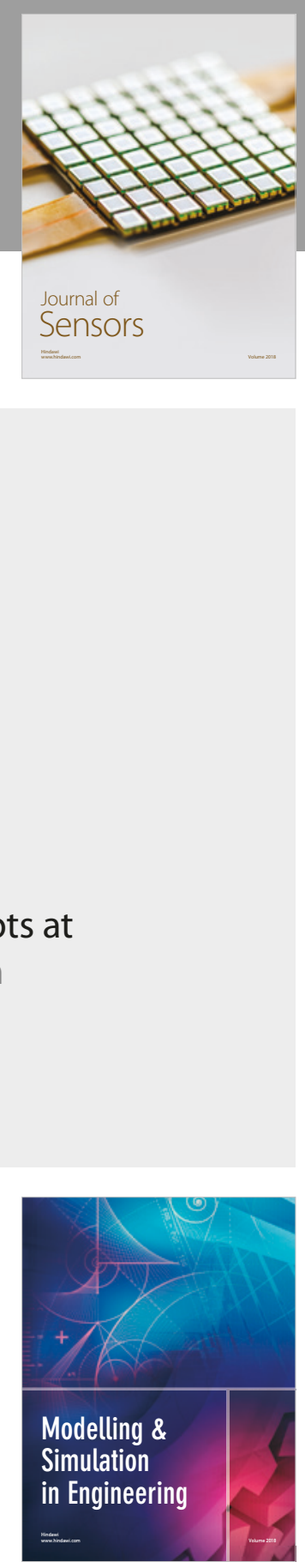

\section{Advances \\ Multimedia}
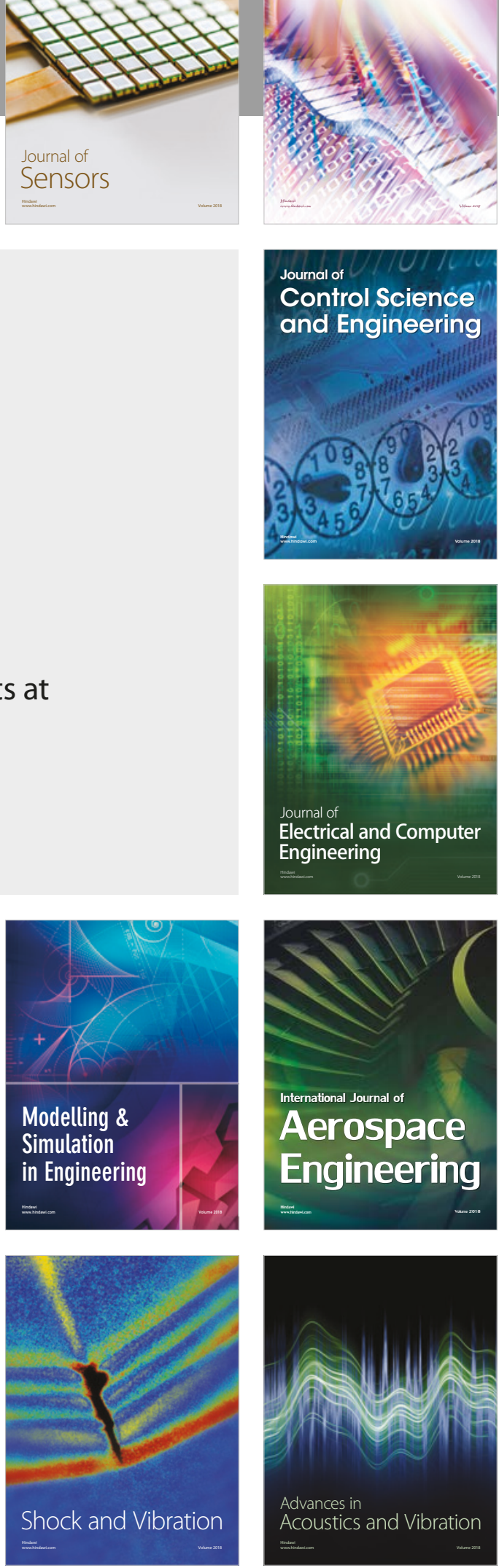